\title{
The effect of fast trading on price discovery and efficiency: Evidence from a betting exchange
}

Bizzozero, Paolo ; Flepp, Raphael ; Franck, Egon

\begin{abstract}
We examine how the presence of fast traders impacts price discovery and efficiency in a real-world setting, i.e., courtsiding, the activity of live betting from a tennis stadium. This setting allows us to isolate the activity of fast-acting traders who have a short-term monopolistic access to important information with respect to other traders who trade based on delayed TV images. Using live-tennis betting data combined with detailed point-by-point match data, our results show that courtsider trading promotes quick price discovery and correctly incorporates new information into prices. We estimate that a simple trading strategy yields a positive trading return to fast traders after the occurrence of important informational events.
\end{abstract}

DOI: https://doi.org/10.1016/j.jebo.2018.09.020

Posted at the Zurich Open Repository and Archive, University of Zurich

ZORA URL: https://doi.org/10.5167/uzh-169997

Journal Article

Accepted Version

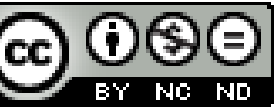

The following work is licensed under a Creative Commons: Attribution-NonCommercial-NoDerivatives 4.0 International (CC BY-NC-ND 4.0) License.

Originally published at:

Bizzozero, Paolo; Flepp, Raphael; Franck, Egon (2018). The effect of fast trading on price discovery and efficiency: Evidence from a betting exchange. Journal of Economic Behavior Organization, 156:126-143.

DOI: https://doi.org/10.1016/j.jebo.2018.09.020 


\title{
The effect of fast trading on price discovery and efficiency: Evidence from a betting exchange
}

\author{
Paolo Bizzozero*, Raphael Flepp, Egon Franck
}

\begin{abstract}
We examine how the presence of fast traders impacts price discovery and efficiency in a real-world setting, i.e., courtsiding, the activity of live betting from a tennis stadium. This setting allows us to isolate the activity of fast-acting traders who have a short-term monopolistic access to important information with respect to other traders who trade based on delayed TV images. Using live-tennis betting data combined with detailed point-by-point match data, our results show that courtsider trading promotes quick price discovery and correctly incorporates new information into prices. We estimate that a simple trading strategy yields a positive trading return to fast traders after the occurrence of important informational events.
\end{abstract}

JEL Classification: G10, G14, L83

Keywords: Price discovery, efficiency, fast trading, speed differentials, betting

\footnotetext{
${ }^{\dagger}$ The authors are grateful to the All England Lawn Tennis Club, Georgina Loth at the French Tennis Federation, and Mark Crawley at IBM for providing the data. The authors thank three anonymous referees as well as seminar participants at the University of Zurich for very helpful comments and suggestions. We are indebted to Helmut Dietl for useful consultation. Finally, we thank Philippe Meier for excellent research assistance.

${ }^{*}$ Corresponding author. University of Zurich, Department of Business Administration, Affolternstrasse 56, CH8050 Zurich, Email: paolo.bizzozero@business.uzh.ch
} 


\section{Introduction}

In modern financial markets, some traders attempt to gain a competitive advantage by investing in speed-enhancing technologies and by using automated trading processes. Their speed advantage allows them not only to receive new important information faster but also to react faster than their competitors (Yadav, 2016). The result of this race for speed is a marketplace characterized by speed differentials, with some traders being faster than others (Shkilko \& Sokolov, 2018). As Haldane (2012, p.252) writes: "Today, [...] to be uninformed is to be slow."

The fastest traders in the marketplace, so-called high-frequency traders (HFTs), use technology to reduce trade latency to the order of microseconds. ${ }^{1}$ HFTs represent an increasingly large share of up to $2 / 3$ of the total trading volume on public stock exchanges (Menkveld, 2018). Thus, understanding the effects of very fast trading on market quality is crucial.

Two important dimensions of market quality are price discovery and efficiency, i.e., the process of quickly and correctly impounding new information into prices (Biais, Foucault, et al., 2014). ${ }^{2}$ From a theoretical perspective, the existence of fast traders has nontrivial effects on these two dimensions. On the one hand, if fast traders are better informed and more skillful, their trading increases price discovery and efficiency. On the other hand, if fast traders incorrectly impound new information into prices, their trading may drive prices away from their fundamentals (Menkveld, 2016). Obtaining direct empirical evidence is difficult because HFTs are heterogeneous and hard to identify (Biais et al., 2014). Moreover, the few studies that establish a clear causal link between fast trading activity and market quality provide contradictory results. For example, Jackson, Jiang, and Mitts (2016) find that HFTs do not cause instantaneous incorporation of

\footnotetext{
${ }^{1}$ Trade latency is generally defined as the length of the process that includes observation of an event, analysis of the information, making a decision, and executing a trade (Riordan \& Storkenmaier, 2012). A microsecond is 0.000001 of a second. As a reference, it takes roughly 0.3 seconds to blink an eye.

${ }^{2}$ Further dimensions of market quality are spreads, liquidity, volatility, and market participation (Biais et al., 2014).
} 
information into prices, whereas $\mathrm{Hu}$, Pan, and Wang (2017) find that HFTs cause full price discovery within 200 milliseconds of a news announcement.

In this article, we uncover how the presence of fast traders impacts price discovery and price efficiency around information events by examining the betting activity of courtsiders during tennis matches. These courtsiders are faster-informed and fasteracting traders because they place live bets on a betting exchange directly from a tennis stadium. Due to the inevitable technological delay in the transmission of images from the stadium to the end receivers, courtsiders who watch the match live in the stadium have a short-term monopolistic access to new important information with respect to traders who watch delayed TV images from their homes (Hutchins, 2014). In other words, the betting market is characterized by speed differentials due to the TV communication delay. Because courtsiders can rapidly trade on the new information, the trading activity in the few seconds after important match events, such as a player winning a point, can be attributed exclusively to them.

Courtsiders on a betting exchange are similar to HFTs on a stock exchange because both are the fastest traders. ${ }^{3}$ The relative speed advantage of courtsiders and HFTs originates mainly from three common factors. First and most important, both choose an advantageous location that gives direct access to not yet fully public information, which is information that is temporarily available to only a subset of all investors. Whereas HFTs co-locate their servers next to the trade matching engine of stock exchanges and receive news feeds directly from the exchanges (Menkveld, 2016), courtsiders sit in the stadium, observe the evolution of the match, and trade in real time on betting exchanges (Hutchins, 2014). Second, both strongly rely on algorithmic trading and on sophisticated computer programs to make decisions in the shortest possible time frames (Hutchins,

\footnotetext{
${ }^{3}$ By no means are we implying that the speed in generating and executing orders is the same for both types of traders: HFTs are known to establish and liquidate positions within microseconds (Securities and Exchange Commission, 2014). This is not the case in courtsiding because the technology used is not sufficiently advanced (Hutchins, 2014). However, when looking at the whole spectrum of trading speed in both markets, both courtsiders and HFTs are situated at the fastest end.
} 
2014; Brogaard, Hendershott, \& Riordan, 2014). Third, both use fast technologies to reduce trading latency. HFTs use microwave and fiber-optic networks together with fast computers (Boehmer, Li, \& Saar, 2018), and courtsiders send data feeds via mobile devices to fast computers that then place or cancel bets (Hutchins, 2014). ${ }^{4}$

The setting of tennis betting offers several advantages compared to earlier HFT studies. The first advantage concerns the type of information available to traders. While HFTs generally rely on indirect information, courtsiders rely on first-hand, easy-tointerpret, material information. Courtsiders observe in first person which player wins the point and how important that point is (Brown, 2012). The second advantage relates to the type of market. In a betting market, the fundamental value of a betting contract becomes observable at the end of the underlying betting event. In this setting, traders form hypotheses about the occurrence of specific events (e.g., "Federer to win") and attach probabilities to these events ("with a $60 \%$ probability"). Throughout the match, these probabilities are continuously updated as new information becomes available. Importantly, the outcome ("Federer won") is actually revealed at the end of the match. Therefore, the efficiency of betting prices can be tested against this indisputable benchmark (Vaughan Williams, 1999). The third advantage concerns the reasons behind trading. Whereas trading on a betting exchange is primarily motivated by the arrival of new information about the fundamental value of a bet (Vaughan Williams, 2009), trading on financial markets can be motivated by other factors, such as portfolio rebalancing, liquidity needs, or imbalances in the limit order book (Ke, Huddart, \& Petroni, 2003). ${ }^{5}$ Overall, tennis betting offers a simple and clean setting for examining the effect of fast trading on price discovery and efficiency.

We use detailed betting data from Betfair, one of the largest betting exchanges worldwide, on 141 men's tennis singles matches played at two major professional tennis

\footnotetext{
${ }^{4}$ Two further, less important, similarities are that both usually trade for their own account (proprietary trading) and cancel a very large share of their limit orders shortly after submission (Hutchins, 2014; Securities and Exchange Commission, 2017).

${ }^{5}$ Uninformed or sentimental trading may occur in both markets.
} 
tournaments, the French Open and the Wimbledon Championships, over the 2009-2014 period. ${ }^{6}$ We complement this information with match data about players, courts, the winner of the match, and the match start and end times. We apply event study methods to examine how prices react after a player wins a set. A set event reveals new important information because, in general, winning a set is an important step toward victory. ${ }^{7}$

We find that the betting prices start updating immediately after set events but before non-stadium traders (such as TV traders) have seen the event, confirming the presence of courtsiders. The cumulative abnormal returns $(C A A R)$ averaged across the 365 set event observations are $3.56 \%$ at the end of the 5 -second courtsiding window after the event. Importantly, courtsiders account for between $60 \%$ and $70 \%$ of the full price reaction when prices stabilize at their new efficient level. We find that the impact of courtsiding is even larger for tie-break sets and close sets, where a player wins the set by a small score margin. The outcome of these sets is more uncertain; thus, information is more valuable. Furthermore, we use a Mincer-Zarnowitz test to show that betting prices are, on average, efficient around the news events (Mincer \& Zarnowitz, 1969). As a final step, we estimate that a simple trading strategy yields a positive trading return of approximately $1.6 \%$ to fast traders when implemented immediately after a close set event. However, fast traders can achieve higher returns by carefully selecting when to implement this trading strategy, for example, during balanced matches. We also find that if the same strategy is not immediately entered after an event, the returns are negative. This implies that slow traders should refrain from trading during pivotal moments of the match because they would lose money to fast traders.

To the best of our knowledge, this article is the first to provide evidence that fasterinformed and faster-acting traders, i.e., courtsiders, promote quick price discovery and correctly incorporate new information into prices, thereby contributing to better market quality. Our findings also have implications for market mechanisms designed to slow

${ }^{6}$ Table A.1 in Appendix A.2 provides the full list of matches.

${ }^{7}$ Appendix A.1 provides a brief introduction to tennis scoring rules and terminology. 
fast traders. For example, Betfair implemented a market orders processing delay of five seconds, also known as a speed bump. However, our results indicate that some fast traders can overcome the speed bump, raising questions about its efficacy. This discussion is relevant as an increasing number of public stock exchanges are introducing speed bumps to level the field between slower investors and predatory HFTs. An example is the IEX, a U.S. electronic exchange championed by Michael Lewis in his 2014 book "Flash Boys", which first introduced a 350-microsecond speed bump for stock trading.

The remainder of this article is organized as follows. Section 2 reviews the relevant literature. Section 3 provides background information about our tennis setting. Section 4 discusses the relationship between courtsiding and price reactions. Section 5 presents the data and summary statistics. Section 6 outlines our empirical methodology and presents the results. Section 7 presents a discussion and concludes the article.

\section{Literature review}

This article is related to the growing literature on speed differentials and informational inequalities caused by fast trading, such as high-frequency trading. From a theoretical point of view, costs and benefits are associated with HFT, as stated by Menkveld (2016, p.11): "HFTs reduce market quality if they are faster to act than others. They increase market quality if they are better informed. If both, the prediction is nontrivial".

On the one hand, faster reaction to news events through automated trading should increase price discovery by accelerating the speed at which prices incorporate new information (Biais et al., 2014). Furthermore, informed HFTs should produce more efficient prices by trading against transitory pricing errors and in the direction of permanent price movements (Kyle, 1985). On the other hand, a market characterized by speed differentials may induce adverse selection. Slow traders may trade less or stop trading if they feel they have a systematic disadvantage, thereby impairing price discovery. Fur- 
thermore, HFTs may play a disfunctional role when they collectively and aggressively trade on a common signal, thereby moving prices away from their fundamentals (Jarrow \& Protter, 2012; Dugast, Foucault, et al., 2014). Additionally, the informativeness of prices may decrease in the medium-term because slower investors may stop conducting fundamental research as they cannot profit from it (Foucault, Hombert, \& Roşu, 2016).

The empirical literature on HFT is vast and complex. ${ }^{8}$ In general, empiricists agree that HFTs are fast acting. For example, Chordia, Green, and Kottimukkalur (2017) find that the prices of S\&P500 exchange traded funds (ETFs) react to macroeconomic announcement surprises within five milliseconds. Accordingly, most studies find that HFT causes better "milliseconds" price discovery (Hendershott, Jones, \& Menkveld, 2011; Hasbrouck \& Saar, 2013; Brogaard et al., 2014; Hu et al., 2017). Using U.K. stock data, Benos and Sagade (2016) find that HFTs collectively contribute approximately $14 \%$ of the total price discovery. However, some studies find that HFT causes price anomalies. For example, Menkveld and Yueshen (2018) investigate the role of HFTs in the 2010 Flash Crash and conclude that their cross-market arbitrage activity made markets more fragile. Concerning short-term price efficiency, Brogaard et al. (2014) find that HFTs increase the efficiency of prices by trading in the direction of permanent price changes. However, over the medium and long terms, HFT strategies, such as order anticipation, and the fact that most HFTs do not perform fundamental research may cause prices to become less efficient (Balp \& Strampelli, 2018).

Empirical studies on HFTs face two major difficulties (Biais et al., 2014). First, identifying the activity of HFTs is challenging because their strategies are heterogeneous, and a formal definition of HFTs is not available. ${ }^{9}$ Empiricists use three approaches to address this issue. The first approach consists of creating a proxy for HFT using publicly

\footnotetext{
${ }^{8}$ Because HFT is a heterogeneous phenomenon, the literature is multi-faceted. Jones (2013), Chordia, Goyal, Lehmann, and Saar (2013), Biais et al. (2014), Securities and Exchange Commission (2014), O'Hara (2015), and Menkveld (2016) provide excellent broad reviews.

${ }^{9}$ The U.S. Securities and Exchange Commission summarizes, in a memorandum, the five main characteristics of HFT firms but reminds that not all these characteristics must be present at the same time to characterize a firm as an HFT firm (Securities and Exchange Commission, 2014, p.4).
} 
available trade information, such as submitted order types, volumes, and speed of order submission (Hasbrouck \& Saar, 2013; Chaboud, Chiquoine, Hjalmarsson, \& Vega, 2014; Weller, 2016). The disadvantage of this indirect approach is that it also captures the activity of algorithmic traders (ATs), not only that of HFTs. ${ }^{10}$ The second approach consists of using the NASDAQ HFT sample, which records trades and quotes from 26 HFT firms (Carrion, 2013; Brogaard et al., 2014; Kirilenko, Kyle, Samadi, \& Tuzun, 2017). However, this data is proprietary, aggregated, and encompasses only a subgroup of HFT firms. The third approach uses account-level data to categorize HFT firms based on various criteria, such as "low inventory at the end of the day" (Benos \& Sagade, 2016; Baron, Brogaard, Hagströmer, \& Kirilenko, 2017). However, the resulting sample may omit some HFT firms and disproportionately represent particular types of firms.

The second difficulty is establishing clear causality between HFT and market quality because HFT strategies and market quality are jointly endogenous (Biais et al., 2014; Baron et al., 2017). For example, whether HFT increases in response to a spike in price volatility or the volatility increases because HFTs start trading more aggressively is difficult to establish. To address these endogeneity concerns, some empiricists look for quasi-experimental settings in which particular events act as the instrumental variable. For example, technological upgrades (Riordan \& Storkenmaier, 2012) and co-location upgrades (Baron et al., 2017) at stock exchanges should impact HFT activity but not market quality.

Because of these two inherent difficulties, only a handful of studies have established direct causality between HFT and market quality. These studies demonstrate causality by analyzing stock prices throughout a period during which a subgroup of fast traders had a short-term monopolistic access to information. Hu et al. (2017) analyze a situation where a small group of fee-paying HFTs were able to receive the Michigan Index of Consumer Sentiment (ICS) two seconds before the general public, whereas Jackson et

\footnotetext{
${ }^{10}$ The main difference between ATs and HFTs is that the latter strongly rely on speed: in this sense, HFTs are a subgroup of ATs that require extremely fast access to markets (Biais et al., 2014).
} 
al. (2016) analyze a situation where 40 HFTs had between several seconds and 7 minutes early access to official SEC filings containing securities disclosures. Surprisingly, these articles' results are contradictory. Hu et al. (2017) find that E-mini S\&P500 futures prices adjusted fully within 200 milliseconds after release to faster traders, with no further price drift thereafter, indicating an efficient price update. Jackson et al. (2016) find that HFTs caused little price discovery within the first 100 seconds of the private window, potentially because SEC filings are difficult to interpret due to their complexity and are sometimes preceded by companies' public reports. ${ }^{11}$

Our article is related to betting studies using sports data. Some authors investigate the semi-strong form of Fama's Efficient Market Hypothesis (EMH) using betting odds during sports events. For example, Croxson and Reade (2014) examine the betting price reaction to goals scored within five minutes before halftime in soccer. Because little or no new information is obtained during halftime, they can test whether the prices quickly adjust to goal events and remain constant thereafter (no price drift). Croxson et al. conclude that the prices update swiftly and fully and that the live betting market is semi-strong-form efficient. However, using similar live soccer data, Choi and Hui (2014) reject the semi-strong form because they find that prices generally underreact to normal news but overreact to surprising news.

Finally, Brown (2012) analyzes the bid-ask spreads of odds on Betfair during the 2009 Wimbledon men's tennis final and asks whether some traders have an advantage due to superior analytical skills or due to access to material information. Brown observes an increase in the live bid-ask spreads prior to and during public information arrival and attributes this increase to an increase in asymmetric information. He considers the possibility that if courtsiders are betting from the stadium, the liquidity providers increase the bid-ask spread to offset losses to courtsiders. However, Brown provides no direct evidence on the effect of courtsiding on price discovery and efficiency.

\footnotetext{
${ }^{11}$ Rogers, Skinner, and Zechman (2017) use the same event but focus only on Form 4 (insider trading information) releases. Their results are qualitatively similar to those in Jackson et al. (2016).
} 
Overall, direct empirical evidence on how the activity of fast traders influences price discovery and efficiency is limited and mixed in financial markets and non-existent in betting markets. This article aims to close this literature gap by considering a simple setting that allows us to overcome the difficulties of previous investigations.

\section{Background information}

To understand the analyses in this article, we first provide important background information on live tennis betting, courtsiding, the TV delay causing asynchronous access to new information, and the speed bump at Betfair.

\subsection{Live tennis betting and courtsiding}

A betting exchange works very similarly to a traditional stock exchange by providing an online market for opinions where traders bet against other traders, without an intermediary, by offering and accepting odds under which they are willing to buy (back) or sell (lay) a certain bet. ${ }^{12}$ Traders can use market orders to buy or sell a bet at the current market price or limit orders if their intention is to buy a bet at a price below the current market price or to sell a bet at a price above the current market price.

In this article, we use data from Betfair, one of the major online betting exchanges worldwide. Betfair revolutionized the sports betting industry in 2000 by introducing the live feature, which allows traders to continuously place or accept bets as the competition unfolds. Tennis live betting is very popular for several reasons. First, trading in tennis is simpler than trading in other sports because there are only two contingencies for each point: a player wins or loses. Most traders follow the match on TV, and whenever new information is observed, they update their bets or place new ones (Brown \& Yang, 2017). Second, liquidity, which is indispensable for trading, is generally high. ${ }^{13}$ Third,

\footnotetext{
${ }^{12}$ Appendix A.3 shows the Betfair trading interface and briefly illustrates the basics of live betting.

${ }^{13}$ The trading volumes on Betfair can be very large. For example, 1.2 billion bets were placed on the exchange in
} 
points are scored frequently, which offers many trading opportunities throughout the match (Landi, 2015). Finally, the many tournaments throughout the year provide an abundance of betting opportunities.

In tennis betting, the fastest way for traders to access relevant information is to sit directly in the stadium during the match. ${ }^{14}$ In this way, courtsiders can observe the score, the physical and mental status of the players, and special situations, such as signs of injury or a call for physiotherapy assistance. As these events generally provide pricing-relevant information, courtsiders transmit live score data to remotely located computers by discreetly tapping on internet-connected portable devices. Then, the computers run the algorithms and automatically bet within tenths of a second (Dickson, 2015). Courtsiders must input the score feeds quickly and precisely, otherwise they would lose money to their main competitors, i.e., other courtsiders. Brad Hutchins, a former tennis courtsider, confirms this in his book: "As more traders come on court, the competition intensifies [...] and it becomes a challenge to be consistently the quickest" (Hutchins, 2014, p. 28-29).

Although trading from the stadium was generally legal under French and British law for the 2009-2014 period covered by our sample, such activity generally violates the terms and conditions of the ticket purchase and therefore is prohibited. ${ }^{15}$ Despite this ban, courtsiding appears to be a common practice, as Brad Hutchins explains: "If you're working on center court at a Grand Slam [tennis tournament], there could be up to twenty other traders gambling on court" (Hutchins, 2014, p. 28). Unfortunately, no official

2014, corresponding to three million bets per day, resulting in a total matched volume of $\$ 92$ billion (Betfair, 2015). In the United Kingdom, the total revenue generated by tennis betting is second only to that generated by soccer betting (Townend, 2016).

${ }^{14}$ Live trading directly from a sports venue is not limited to tennis. Different terms exist for other sports, such as pitchsiding in cricket and soccer.

${ }^{15}$ For example, Article 24 of the ticket terms and conditions at Wimbledon (2017) reads: "Betting is prohibited in the Grounds at all times", and Article 19 specifies that "[t] he use of photographic equipment, mobile telephones, computers, tablets or other electronic devices, communication devices, audio-visual equipment or radios must not [...] supply or transmit data for the purposes of betting or gambling (or assisting for these purposes)." The Australian State of Victoria, where the Australian Open Grand Slam tournament is held, is the only region where courtsiding is a crime and comes with a prison sentence of up to 10 years (Parliament of Victoria, 2013). We note that courtsiding and match-fixing are not the same practice (UK Gambling Commission, 2016). 
statistics about this phenomenon are publicly available. The news media occasionally reports episodes of courtsiders who have been ejected from tennis tournaments. Probably the most famous case involved Dan Dobson, a 22-year-old who was arrested at the 2014 Australian Open because he was sending live scores to a betting agency (Cox, 2015). The case was later dropped because the necessary legislation to arrest him did not exist. In 2015, a BBC investigation revealed that approximately 75 courtsiders were sitting at the 2014 Wimbledon final (Anderson, 2015). In 2017, the New York Times wrote that 20 courtsiders were caught at the 2016 U.S. Open and eight at the 2017 U.S. Open (Rothenberg, 2017). If spotted, courtsiders are ejected from the tournament and put on a "black list" that is shared with other tournaments. At times, courtsiders have received lifetime bans and fines of up to $\$ 250,000$ (Hutchins, 2014; Hays, 2017).

\subsection{The speed differential}

In contrast to courtsiders, off-stadium traders rely on communication technologies to stay informed about the progress of the match. The most comprehensive source of information for outsiders is the "live" TV broadcast of the match, which provides not only score information but also key information, such as a player's fatigue level, confidence, or tactics. However, TV images may miss important match scenes and, most importantly to our study, are significantly delayed in comparison to the real match. On its website, Betfair clearly indicates that any transmissions described as "live" by broadcasters may actually be delayed and that the extent of such delay may vary, depending on the setup through which they are receiving pictures or data (Betfair, 2017b). ${ }^{16}$

Accurate estimates of the length of the TV delay are difficult due to the large number

\footnotetext{
${ }^{16}$ In the terms and conditions for betting, Betfair writes the following: "Although the current score, time elapsed, video and other data provided on this site is sourced from "live" score feeds provided by third parties, you should be aware that this data may be subject to a time delay and/or be inaccurate. Please also be aware that other Betfair customers may have access to data that is faster and/or more accurate than the data shown on the Betfair site. If you rely on this data to place bets, you do so entirely at your own risk. Betfair provides this data AS IS with no warranty as to the accuracy, completeness or timeliness of such data and accepts no responsibility for any loss (direct or indirect) suffered by you as a result of your reliance on it."
} 
of determining factors. Kooij, Stokking, van Brandenburg, and de Boer (2014) measure the delay in live TV broadcasts in the Netherlands. They estimate that a minimum delay of four seconds is introduced by the encoding and modulation of the images, on top of which one should add between one and six seconds for transmission. ${ }^{17}$ This corresponds to the delay mentioned by Brad Hutchins: "If everyone gambling at home is watching a television feed that is delayed by five seconds, you have just five seconds to take advantage" (Hutchins, 2014, p. 28). Due to this inevitable technological delay in the transmission of images from the stadium to the end receivers, courtsiders who watch the match live in the stadium have a speed advantage and thus a short-term monopolistic access to new information. In this sense, the live betting market is characterized by a speed differential of at least five seconds.

\subsection{The speed bump}

In an effort to slow courtsiders, Betfair implemented a bet processing delay, a so-called speed bump. The speed bump imposes a delay of exactly five seconds between the time at which a market order (a new bet) is submitted and the time at which it is logged on the exchange and is eventually matched with outstanding orders (Betfair, 2017a). ${ }^{18}$ In practice, once the trader has entered the stake and confirmed the market order, Betfair begins a five-second countdown, at the end of which the market order is logged on the exchange. If the counterparty has not yet canceled the outstanding bet (within five seconds), the two orders are matched; if the counterparty has canceled the outstanding bet, no transaction occurs.

\footnotetext{
${ }^{17}$ Concerning the transmission of TV images, the length of the delay can vary greatly depending on the transmitting technology (satellite is slower than terrestrial, while internet streaming is the slowest), the quality (high definition is slower than standard definition), the subscription (digital is generally slower than analog TV), and the broadcaster (which use different hardware). The delay increases with the geographical distance between the event, the local broadcaster, and the household (Kooij et al., 2014). Fig. 1 in Kooij et al. (2014) illustrates the various steps of a TV content delivery chain: "live" TV broadcasts differ from pre-recorded content (such as a TV series) because they introduce additional steps (and delays) due to filming and transmission to the broadcaster from the event location. Furthermore, as traders on a betting exchange are dispersed around the world and use different technologies, an attempt to determine the actual average delay for all the traders is unrealistic. Other information sources, such as internet scoreboards, are also delayed (Landi, 2015).

${ }^{18}$ Changing the odds of a limit order is treated as placing a new market order and is subjected to the speed bump.
} 
Importantly, however, some traders circumvent the speed bump by exploiting the fact that a limit order can be canceled without delay (Cox, 2015). Therefore, they place two limit orders, one on each player, and then cancel the wrong position once the new score data are received. In this way, the fastest traders can profit from their time advantage despite the speed bump. For example, courtsiders who observe Federer winning a set will immediately cancel their outstanding orders for "Federer to lose" but not those on "Federer to win". Contemporaneously, slower traders, who are still unaware of the outcome of the set, will see their market orders matched on the wrong side of the market, i.e., "Federer to lose". ${ }^{19}$ In the next section, we explain how bypassing the speed bump impacts betting prices.

\section{Courtsiding and price reaction}

Fig. 1 presents three scenarios regarding the hypothetical impact of courtsiding on prices. In all scenarios, given the minimum length of the TV delay, we assume that the speed differential between courtsiders and non-stadium traders is five seconds. ${ }^{20}$ The grey line indicates the assumed time pattern of the cumulative returns computed from the betting odds. ${ }^{21}$ The horizontal axis represents the time elapsed (in seconds) after the event, which occurs at time zero.

Scenario 1 depicts a situation without courtsiders: all traders are TV traders. All traders see the delayed TV images five seconds after the actual event and place their market bets. After a five-second speed bump, the new orders are logged on the exchange. Thus, the price adjustment begins, at the earliest, ten seconds following the event.

\footnotetext{
${ }^{19}$ Dan Dobson, a former courtsider, confirms this practice in an interview with the BBC: "We had an automated system whereby the point data would come in and then we would cancel any [outstanding] bets that we had in the market that we deemed were at the wrong price [...]. Then we would place bets straight back into the market that we deemed were now the correct price" (Cox, 2015).

${ }^{20}$ This is a conservative assumption. As Kooij et al. (2014) shows, the actual TV delay may be much longer than five seconds.

${ }^{21}$ In Section 6, we describe the event study methodology in detail. We compute the returns using the odds-implied winning probability of the player who wins the set and average these values over all events. If a player wins a set, his match-winning odds should decrease to reflect his higher chances to win the match. This explain the positive reaction depicted in Fig. 1.
} 
Scenario 1. Without courtsiders.

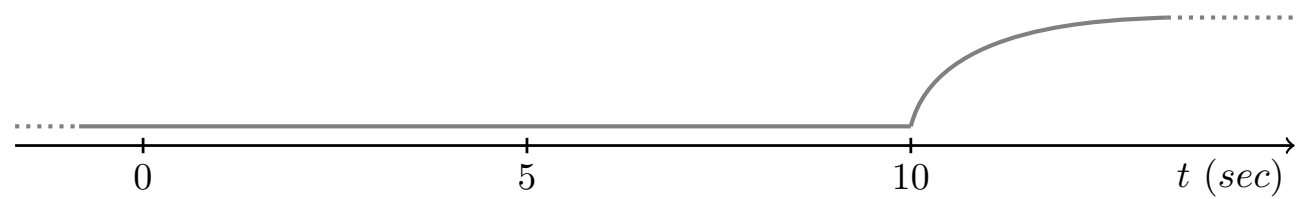

Scenario 2. With courtsiders.

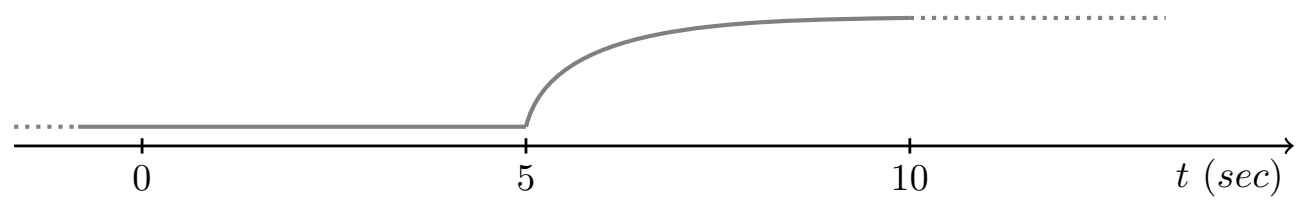

Scenario 3. With courtsiders circumventing the speed bump.

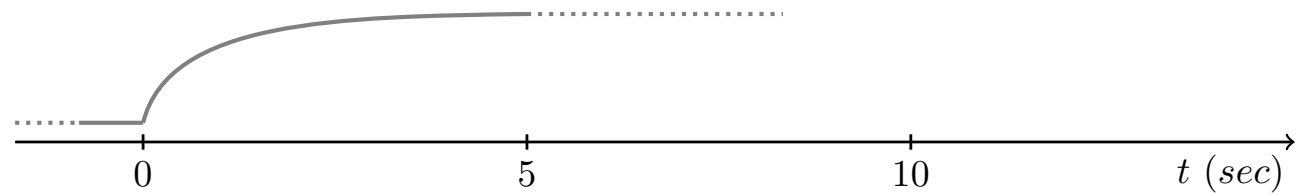

Figure 1 The timeline of the price adjustment under three scenarios. Time is in seconds, and zero corresponds to the second at which the event occurs. The line indicates the assumed time pattern of the cumulative average returns computed from the betting odds.

Scenario 2 depicts a situation with courtsiders and non-stadium traders. If courtsiders observe the event as it occurs and place new market orders that are subjected to the speed bump, the price adjustment begins, at the earliest, five seconds following the event. However, non-stadium traders who see the event at second five may cancel, without any delay, their limit orders on the wrong side of the market. In this scenario, we cannot distinguish between the activity of courtsiders and that of non-stadium traders because the trading activity of both types of traders occurs at $t=5$. Nonetheless, the price adjustment begins, at the earliest, five seconds following the event.

Scenario 3 represents a situation that most closely resembles the reality depicted by former courtsiders (Hutchins, 2014; Cox, 2015). Scenario 3 differs from Scenario 2 because some courtsiders circumvent the speed bump by canceling their limit orders on the wrong side of the market without any delay, as discussed above. In this case, we 
should observe a significant price adjustment within five seconds following a news event, i.e., during the courtsiding window. Thus, compared to situations without courtsiders (Scenario 1), the price discovery in the presence of sophisticated courtsiders is accelerated by roughly ten seconds, from $t=10$ to $t=0$. Concerning the price efficiency, once all the new information is correctly incorporated into prices, we should observe no price drift thereafter, indicating that prices have updated to their new efficient level. Therefore, by measuring the proportion of the price update that occurs during the 5 -second courtsiding window, we can measure the courtsiders' contribution to the price update. Ultimately, if the prices update according to Scenario 3, it would mean that courtsiders, on average, correctly impound new information into prices.

\section{Data}

Our sample consists of 141 Grand Slam men's singles matches played between 2009 and 2014 at Roland Garros (61 matches) and at Wimbledon (80 matches). The betting data originate from Betfair and are provided by Fracsoft, the official data vendor. For every 1,296,688 seconds in our sample, we have the best back and lay odds. The total matched volume over 141 matches is $\$ 2.95$ billion, $85 \%$ of which is generated during live betting. The average live matched volume is roughly $\$ 18$ million.

Detailed match data are provided by IBM, the official supplier of information technology to both tennis tournaments. Beyond general information about the match, such as players and the start and end times, the IBM data also contain 31,018 point-level observations of the score, time (exact to the second), and winner of each point. The score is fed into the system directly by the match umpire using a computer, whereas other statistics are collected by analysts who attend the match and manually feed the data into the system. ${ }^{22}$

\footnotetext{
${ }^{22}$ The International Tennis Federation (ITF), the governing body of tennis, requires the umpires to "timely and accurately" enter the points in their computers throughout the match.
} 
Table 1 provides summary statistics. Betfair fixed the speed bump to five seconds. An average match in our sample lasts 155 minutes and consists of 3.6 sets, 36 games, and 221 points. Our sample is heterogeneous, containing matches from the first stage up to the finals with a total of 83 unique players. Usually, semifinal and final matches attract larger volumes than do first-round matches, as shown by the $\$ 70.5$ million matched during the 2013 Wimbledon semiffinal between Djokovic and Del Potro.

Table 1 Summary statistics.

\begin{tabular}{|c|c|c|c|c|c|}
\hline Variables & Mean & Std. dev. & Min. & Max. & $N$ \\
\hline \multicolumn{6}{|l|}{ Panel A: betting odds } \\
\hline Live matched volume (mio $\$$ ) & 18.1 & 19.4 & 0.2 & 70.5 & $1,296,688$ \\
\hline Live speed bump length (seconds) & 5 & 0 & 5 & 5 & $1,296,688$ \\
\hline \multicolumn{6}{|l|}{ Panel B: match information } \\
\hline Duration (minutes) & 154.7 & 50.1 & 69.9 & 284.8 & 141 \\
\hline Number of points & 221.2 & 66.1 & 117 & 437 & 141 \\
\hline Number of sets & 3.6 & 0.7 & 3 & 5 & 141 \\
\hline Number of games (in a match) & 35.8 & 10.1 & 20 & 77 & 141 \\
\hline Number of games (in a set) & 9.9 & 2.2 & 6 & 30 & 141 \\
\hline
\end{tabular}

Notes: The table reports the summary statistics for the 141 men's singles matches in our sample. The matches were played at the French Open and at the Wimbledon Championships between 2009 and 2014 (see Table A.1 in the Appendix). In Panel A, we report the statistics for the betting odds from Betfair. In Panel B, we report the match statistics from IBM.

\section{Empirical analyses}

\subsection{Event study}

The aim of our event study is to quantify the extent to which courtsiding affects the betting odds reaction after various news events. Before we present the results, we briefly describe the news events and explain the event study methodology.

\subsubsection{News events}

The aim of our event study is to quantify the extent to which courtsiding affects the betting odds reaction after various news events. Thus, in this section, we describe the news events and explain the event study methodology.

Our baseline news event is a player winning a set because it satisfies three important 
criteria. First, the end of a set is generally an important news event because at the French Open and at Wimbledon, the first player to win three sets wins the match. Therefore, a player's probability of winning the match generally increases after winning a set. Second, the end of a set is an easily observable event and is always proceeded by a "setpoint". Third, a 120-second break follows the end of each set. This is advantageous because our event study results are less affected by overlapping and confounding events in the seconds following the end of a set. ${ }^{23}$ Finally, we exclude the last set from all analyses because the betting market is immediately closed when a player wins the match. ${ }^{24}$

Our baseline sample includes 365 set events from 141 matches. Fig. 2 illustrates our data. The figure shows the evolution of Del Potro's odds-implied winning probability (henceforth, WP) over the match he played against, and lost to, Djokovic at Wimbledon on 5 July $2013 .^{25}$ In general, this example shows that betting prices quickly react to new information revealed throughout the match: when the match started, Del Potro's WP was 15\%, but his WP dropped to $8 \%$ after he lost the first set.

However, if one player wins a set by a large margin, the betting odds are already updated during the set and move only by a small amount when the set ends. In our example, Del Potro won a game when Djokovic was serving (a so-called break) in the second set, resulting in an increase in Del Potro's WP by roughly $10 \%$, which is visible in Fig. 2. When Del Potro eventually won the second set, the odds moved by only a small amount because this outcome was already anticipated. This example shows that, if the score gap before the last point of a set is large, the set event may not be very

\footnotetext{
${ }^{23}$ Croxson and Reade (2014) consider the 15-minute halftime break in soccer matches as a "low-information period" because important information is rarely revealed during the break. Similarly, in tennis, little information is revealed during the break between sets, except when players suddenly start showing signs of fatigue, stress, or pain.

${ }^{24}$ At the French Open and Wimbledon, a match is played as the best of five sets. Since we do not include the last set when the match ends, we analyze between two and four set events per match. The "Number of sets" reported in Table 1 corresponds, however, to the statistics for the original sample before excluding the match points.

${ }^{25}$ In a live betting market, the price of a betting asset throughout the match, such as "Del Potro to win the match", is represented by its live odds (we explain this in Appendix A.3). By computing the inverse of these odds, we can derive the aggregate traders' belief about a given player's probability of winning the match (the WP) at any moment of the match (Vaughan Williams, 2009).
} 


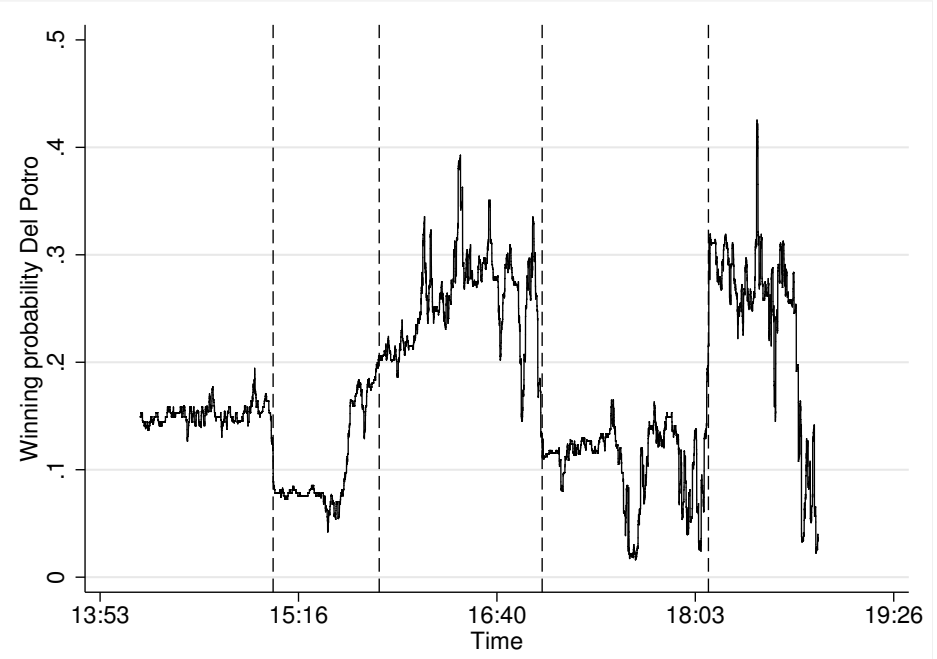

Figure 2 Del Potro's odds-implied match winning probability for his 5 July 2013 semifinal match against Djokovic at Wimbledon. Del Potro lost in five sets after more than four hours of play with the following score: 5-7; 6-4; 7-6 (tie-break: 7-2); 6-7 (tie-break: 6-8); 3-6. A total of roughly $\$ 74.8$ million was bet on this match, 94\% of which (\$70.5 million) was placed live. The vertical dashed lines indicate the end of a set (excluding the last one because we exclude match points).

important.

Therefore, as a second step, we use the end of a set won by a small margin as news event because the outcome of the set is decided only in the last few points played and is therefore important and informative. We do so by considering two different subsets. (1) We consider 79 "tie-break sets", i.e., sets decided at the tie-break. ${ }^{26}$ A tie-break decides the outcome of very balanced sets, as such, it is generally more difficult to predict who will win the set. In our sample, a tie-break lasts, on average, approximately eight minutes (with a minimum of four minutes and a maximum of 17 minutes). In our example from Fig. 2, both the third and fourth sets were decided by tie-break. (2) We consider 81 "close sets" composed of 25 "close $7-5$ sets" and 56 "close tie-break sets". ${ }^{27}$ The "close 7-5 sets" represent sets won 7 games to 5 with a final game whose score difference is small, either 40-30 or advantage. Such a close 7-5 set is represented in Fig. 2, when Del Potro lost the first set 5 games to 7 , resulting in a significant decrease in his WP

\footnotetext{
${ }^{26}$ As we explain in Appendix A.1, a tie-break is won when a player wins seven points and there is a margin of at least two points over the opponent (e.g., 7-5, 8-6, or 9-7).

${ }^{27}$ We thank an anonymous referee for this suggestion.
} 
from $15 \%$ to $8 \%$. The "close tie-break sets" represent sets won in tie-breaks and when the last game is won by a small score margin, i.e., by a two- or three-point differential. Such a close tie-break set is represented in Fig. 2, when Del Potro won the fourth set by a two-point margin ( 8 points to 6 ), resulting in a jump in his WP from $4 \%$ to $33 \%$.

In summary, we analyze various set events. We begin with all 365 sets and then consider different subsamples representing sets won by a small margin: 79 tie-break sets and 81 close sets. The subsampling allows us to examine how fast traders, and thus prices, react to important events.

\subsubsection{Methodology}

We follow the classic methodology presented by MacKinlay (1997). Fig. 3 summarizes the timeline of the event study. We define the moment that a player wins a set as the event time $(t=0)$. The event window spans from $t_{1}=-2$ to $t_{2}=20$ and lasts 23 seconds ( $L=23$ ). Given that a 120 -second break follows the end of each set, the event window does not include confounding events. We account for the possibility that some traders anticipate the outcome of the point or that the umpire may update the score with a short lag by letting our baseline event window begin two seconds before the actual event. According to the ITF rules, the time between two consecutive points should be 20 seconds. In our sample, the median elapsed time is 22 seconds; therefore, there should not be informational spillover from the previous point.

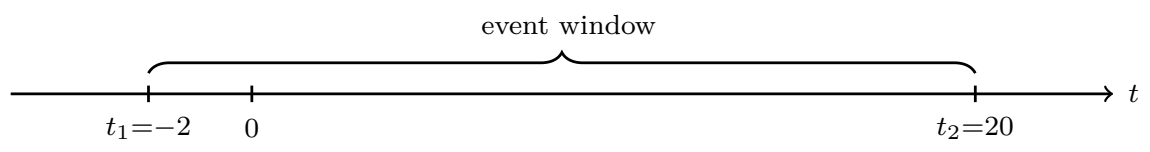

Figure 3 Timeline of the event study, where $t$ represents the time, in seconds, during a match. The news event occurs at $t=0$.

Because we want to analyze the reaction of the odds for the player who won the set, we consider only the odds of the set winner. For each second $t$ surrounding an event, we compute the average mid-odds (bid-ask midpoints) from the best back (back $)$ and sell 
odds $\left(\right.$ layt $\left._{t}\right)$ as follows:

$$
\operatorname{mid}_{t}=\frac{b a c k_{t}+l a y_{t}}{2}
$$

The mid-odds, which are expressed in decimal terms, can range from 1.01 to 1000 . Then, we derive the implied winning probability by taking the inverse of the mid-odds $\left(W P_{t}=\frac{1}{\text { midt }_{t}}\right)$, which approaches $99 \%$ when the mid-odds approach 1.01 . Finally, we compute the actual returns from the odds-implied winning probability as follows:

$$
R_{t}=\frac{W P_{t}}{W P_{t-1}}-1
$$

When a player wins a set, the odds should adjust downward and the odds-implied winning probability should adjust upward, resulting in a positive return.

Because all bets are zero-sum games (when commissions are not considered), we assume that the normal returns, i.e., the returns in the absence of the event, are zero over the event window. ${ }^{28}$ Thus, the returns from Eq. 2 represent the abnormal returns for the event study. As the final step, we aggregate the returns along the event dimension to generate the average abnormal returns $A A R_{t}$ and along the time dimension to compute the cumulative average abnormal returns $C A A R_{\left(t_{1}, t_{2}\right)}=\sum_{t=t_{1}}^{t_{2}} A A R_{t}$.

\subsubsection{Results}

Fig. 4 presents the cumulative average abnormal returns $(C A A R)$ and the corresponding $95 \%$ confidence interval over the event window for the three types of events. ${ }^{29}$

Starting with the set events, Fig. 4(a) shows a significant positive reaction in the betting odds in the first seconds immediately following an event. Most importantly, after the first five seconds following the set event, the $C A A R$ is $3.56 \%$ and is statisti-

\footnotetext{
${ }^{28}$ We thank an anonymous referee for suggesting this. Alternatively, we also estimate the normal return for each event as the arithmetic mean of the returns over the estimation window spanning from $t=-10$ to $t=-3$. We then compute the abnormal returns for each event by subtracting the normal returns from the actual returns over the event window. This procedure yields similar results (untabulated).

${ }^{29}$ In Appendix A.4, Table A.2 reports the results in tabular form.
} 
(a) Set event

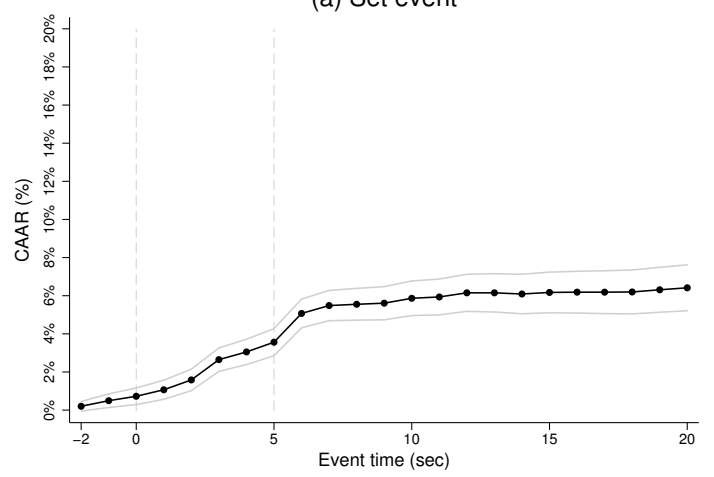

(b) Tie-break set event

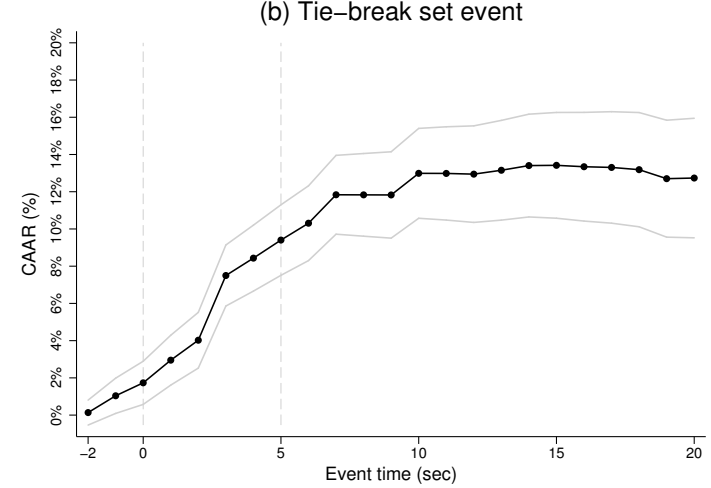

(c) Close set event

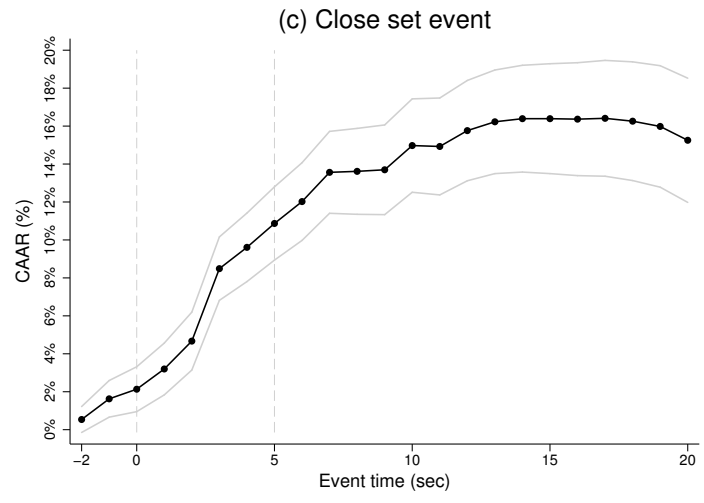

Figure 4 Cumulative average abnormal returns $(C A A R)$ for three events: (a) set events, (b) tie-break set events, and (c) close set events. The gray lines represent the $95 \%$ confidence intervals.

cally significant at the $1 \%$ level. This result implies that some sophisticated courtsiders overcome the speed bump, as assumed in Scenario 3. Most of the new information is fully incorporated into the betting odds within twelve to thirteen seconds, after which the $C A A R$ stabilizes at approximately $6 \%$, indicating that prices have updated to their new efficient level. Thus, courtsiding accounts for roughly $60 \%$ of the full price reaction. Finally, the largest return $(A A R)$ of $1.51 \%$ occurs at second six. This result suggests that courtsiders not only cancel wrong outstanding limit orders but also immediately place new market orders, which are delayed by the speed bump, at the price that they deem to be correct.

Fig. 4(b) presents the $C A A R$ over the event window for the 79 tie-break set events 
(sets won at the tie-break). After the first five seconds following a news event, the $C A A R$ is $9.4 \%$ and is statistically significant at the $1 \%$ level. Overall, the $C A A R$ pattern is similar to that of the set events, with three main differences. First, the total adjustment of approximately $13 \%$ is twice as large as that for set events because a tie-break is a very important information event whose outcome is difficult to predict. Second, the largest average abnormal return $(A A R)$ of $3.48 \%$ occurs earlier at $t=3$. Courtsiders likely attempt to trade even faster to gain an advantage over other courtsiders, resulting in a faster and larger price updates. Third, courtsiders' trading during the first five seconds causes approximately $72 \%$ of the full price reaction, which is larger than the corresponding figure for set events.

Fig. 4(c) presents the $C A A R$ over the event window for the 81 close set events. After the first five seconds following a news event, the $C A A R$ is $10.8 \%$ and is statistically significant at the $1 \%$ level. The $C A A R$ pattern of the close set events is very similar to the pattern of the tie-break events, except that the price jump is larger for close set events due to their importance. Additionally, the price requires two more seconds to stabilize to the new efficient level. Finally, similarly to the other events, courtsiders are responsible for approximately $66 \%$ of the full price reaction.

Taken together, our results show that the speed and amount of price discovery are affected by courtsiding. Courtsiders substantially contribute to advancing the beginning of the price discovery process and are responsible for a large fraction of the price update. By delaying the market orders of the courtsiders, the speed bump somewhat delays the full price discovery process. The tie-break set and close set event results show that courtsiders are aware that during pivotal moments, a faster reaction is even more valuable for gaining an edge over other fast traders. 


\subsection{Mincer-Zarnowitz efficiency test}

In this subsection, we exploit an important feature of betting markets to examine how the predictive ability of prices, and thus their efficiency, evolves around news events. In a betting market, the fundamental value of each bet is unambiguously revealed when the outcome of the underlying event - in our case, the winner of the match - is observed (Brown \& Yang, 2017). The actual outcome serves as a benchmark against which the efficiency of the odds can be tested (Vaughan Williams, 2009). ${ }^{30}$ Therefore, we employ the Mincer and Zarnowitz (1969) (MZ) regression test to examine whether the oddsimplied winning probability of the player alone is sufficient to predict the match outcome around important news events.

The MZ regression model is specified as follows:

$$
\text { outcome }_{i t}=\alpha_{0}+\alpha_{1} \text { pwin }_{i t}+\beta_{0} \text { postevent }_{i t}+\beta_{1} \text { pwin }_{i t} \times \text { postevent }_{i t}+\epsilon_{i t},
$$

where the subscripts $i$ and $t$ denote the player and time in seconds (from $t=-10$ to $t=5)$, respectively. In this regard, we include the winner and the loser of the set. The dependent variable outcome represents the outcome of the match for player $i$, which is 1 if he wins the match and 0 otherwise. The main independent variable, pwin, represents the odds-implied player's probability of winning the match as computed in Section 6.1.2. We also include two additional variables: a postevent, which is a dummy that takes a value of one for the length of the courtsiding window, i.e., from $t=0$ to $t=5$, and an interaction term pwin $\times$ postevent. The general null hypothesis of the MZ-test refers to a joint test of $\alpha_{0}=1-\alpha_{1}=\beta_{0}=\beta_{1}=0$, meaning that the betting prices alone are sufficient to predict the match outcome (Mincer \& Zarnowitz, 1969).

From a theoretical point of view, a slope coefficient $\hat{\alpha}_{1}$ close to one indicates that the odds are efficient before the news event when the postevent equals zero. If the prices are

\footnotetext{
${ }^{30}$ As we explain above, the inverse of a player's match odds can be interpreted as his probability of winning the match as estimated by the market.
} 
already efficient before the news event $\left(\hat{\alpha}_{1} \approx 1\right)$ and courtsiders do not introduce any bias into prices, we expect that the interaction coefficient will be close to zero $\left(\hat{\beta}_{1} \approx 0\right)$ or, equivalently, that $\hat{\alpha}_{1}+\hat{\beta}_{1} \approx 1$. Under this scenario, the odds are also efficient after the event, meaning that new information is correctly incorporated into prices by courtsiders. By contrast, if the prices are efficient pre-event $\left(\hat{\alpha}_{1} \approx 1\right)$ but the interaction coefficient is significantly different from zero $\left(\hat{\beta}_{1} \lessgtr 0\right)$, we would conclude that courtsiders' activity negatively affects price efficiency by introducing a bias $\left(\hat{\alpha}_{1}+\hat{\beta}_{1} \lessgtr 1\right)$. The results of Brown, Reade, and Vaughan Williams (2018) provide an example in which prediction market prices become less efficient after the news events. They use the same MZ-test to investigate how opinion poll releases affected the ability of Intrade prices to predict the outcome of the 2012 U.S. Presidential election. Brown et al. find that the prices are inefficient before the news release and, surprisingly, become even less efficient during the first hour after the news release. Brown et al. find that this decrease in price efficiency is due to the increased activity of inexperienced traders. As more experienced traders start trading, the price bias is reduced.

Table 2 presents our results for Eq. 3 using set, tie-break set, and close set events. The findings of interest are reported in columns (2), (4), and (6). ${ }^{31}$ In general, the MZtest shows that the odds are efficient. The MZ joint null hypothesis is not rejected for all set events $(\mathrm{F}-$ value $=1.75)$ and for the tie-break set events $(\mathrm{F}-$ value $=1.20)$. However, it is barely rejected for the close set events $(\mathrm{F}-$ value $=2.06)$. Most importantly, a closer look reveals that the $\hat{\alpha}_{1}$ coefficient for pwin is not significantly different from one throughout most specifications, indicating that the odds on their own provide an efficient forecast of the outcomes already before the news event. ${ }^{32}$ Furthermore, the $\hat{\beta}_{1}$ interaction coefficient is not significantly different from zero, suggesting that courtsiders correctly incorporate new information into prices without introducing a bias. Overall, the results show that

\footnotetext{
${ }^{31}$ Columns (1), (3), and (5) report the results when only a constant and pwin are included. These results serve as a baseline reference.

${ }^{32} \mathrm{An} \hat{\alpha}_{1}$ significantly larger than one indicates a favorite-longshot bias. This bias has been found in several previous betting papers. See Brown and Yang (2017) for a discussion of the possible causes.
} 
the betting odds efficiently update over the courtsiding window.

Table 2

Mincer-Zarnowitz efficiency test.

\begin{tabular}{|c|c|c|c|c|c|c|}
\hline & \multicolumn{6}{|c|}{ Dependent variable: outcome } \\
\hline & \multicolumn{2}{|c|}{ Set event } & \multicolumn{2}{|c|}{ Tie-break set event } & \multicolumn{2}{|c|}{ Close set event } \\
\hline & (1) & $(2)$ & (3) & $(4)$ & $(5)$ & (6) \\
\hline constant & $\begin{array}{l}-0.046^{* *} \\
(0.021)\end{array}$ & $\begin{array}{l}-0.047^{* *} \\
(0.022)\end{array}$ & $\begin{array}{l}-0.022 \\
(0.056)\end{array}$ & $\begin{array}{l}-0.024 \\
(0.058)\end{array}$ & $\begin{array}{l}-0.074 \\
(0.047)\end{array}$ & $\begin{array}{l}-0.076 \\
(0.050)\end{array}$ \\
\hline pwin & $\begin{array}{l}1.095^{* * *} \\
(0.044)\end{array}$ & $\begin{array}{l}1.096^{* * *} \\
(0.044)\end{array}$ & $\begin{array}{l}1.052^{* * *} \\
(0.112)\end{array}$ & $\begin{array}{l}1.056^{* * *} \\
(0.116)\end{array}$ & $\begin{array}{l}1.157^{* * *} \\
(0.094)\end{array}$ & $\begin{array}{l}1.158^{* * *} \\
(0.099)\end{array}$ \\
\hline postevent & & $\begin{array}{l}0.001 \\
(0.002)\end{array}$ & & $\begin{array}{l}0.007 \\
(0.008)\end{array}$ & & $\begin{array}{l}0.003 \\
(0.010)\end{array}$ \\
\hline pwin $\times$ postevent & & $\begin{array}{l}-0.001 \\
(0.003)\end{array}$ & & $\begin{array}{l}-0.011 \\
(0.017)\end{array}$ & & $\begin{array}{l}-0.003 \\
(0.020)\end{array}$ \\
\hline $\mathrm{N}$ (seconds) & 11,680 & 11,680 & 2,528 & 2,528 & 2,592 & 2,592 \\
\hline Number of events & 365 & 365 & 79 & 79 & 81 & 81 \\
\hline Adjusted $R^{2}$ & 0.652 & 0.652 & 0.470 & 0.470 & 0.554 & 0.554 \\
\hline F-statistic & $617.89^{* * *}$ & $262.71^{* * *}$ & $87.43^{* * *}$ & $42.07 * * *$ & $149.78^{* * *}$ & $85.02^{* * *}$ \\
\hline t-test of $\alpha_{1}=1$ & $4.71^{*}$ & $4.61^{*}$ & 0.21 & 0.23 & 2.76 & 2.53 \\
\hline MZ-test & $3.05^{*}$ & 1.75 & 2.02 & 1.20 & $3.68^{* *}$ & $2.06^{*}$ \\
\hline
\end{tabular}

Notes: The table reports the results of the Mincer-Zarnowitz regressions. The dependent variable, outcome, represents the outcome of the match for the player $i$ (both the winner and loser of the set), which is one if he wins the match and zero otherwise. The variable pwin is the odds-implied player's probability of winning the match. The variable postevent is equal to one for seconds zero to five following an event, i.e., the courtsiding window. The " $\mathrm{F}$-statistic" is the $\mathrm{F}$-value for the overall significance. The "t-test of $\alpha_{1}=1$ " reports the $\mathrm{t}$-value for the test $\alpha_{1}=1$. The "MZ-test" reports the $\mathrm{F}$-value for the joint test $\alpha_{0}=1-\alpha_{1}=\beta_{0}=\beta_{1}=0$. The data are at the second level from seconds $t=-10$ to $t=5$. The robust standard errors adjusted for clustering at the match level are provided in parentheses. In all models, *, **, and *** denote significance at the $10 \%, 5 \%$ and $1 \%$ levels, respectively.

\subsection{Trading strategy}

As a final step, we analyze whether courtsiders can earn positive returns by betting from the stadium. By knowing before others in which direction the betting odds are likely to move, a courtsider may use a simple "sequential back-lay" trading strategy. Accordingly, the courtsider first backs the player who wins a set and, for example, 20 seconds later, lays that same player. By taking both sides of the market, i.e., sequentially betting for and against the same player, the courtsider locks in a certain payoff regardless of the 
final outcome of the match. ${ }^{33}$ Importantly, the payoff will be positive only if the back-lay odds difference $\left(b_{a c k}-l_{0} y_{20}\right)$ is positive and will be larger if that difference is larger. Therefore, courtsiders focus on speed only when backing the player to get higher back odds. Then, they can wait up to two minutes, the length of the pause between sets, to close the trade at the updated, lower lay odds.

As an illustration, a courtsider quickly stakes $\$ 100$ to back the player (P1) who has just won the set at back odds of $2.0\left(b_{a c k}=2\right)$. Then, the courtsider waits for the lay odds to decrease and closes the position by staking $\$ 105$ to lay P1 at the lower lay odds of $1.90\left(\operatorname{lay}_{20}=1.9\right)$. The gross return locked in by this strategy is $5 \%$, regardless of the final outcome: if $\mathrm{P} 1$ wins the match, the back-bet win is $\$ 100$ and the lay-bet loss is $\$ 95$, yielding a gross profit of $\$ 5$ (or a net profit of $\$ 4.75$ after deducting the $5 \%$ commission on winning bets); if $\mathrm{P} 1$ loses the match, the back-bet loss is $\$ 100$ and the lay-bet gain is $\$ 105$, yielding exactly the same profit. ${ }^{34}$

To assess the return that a courtsider could have earned by using this sequential back-lay strategy, we assume that the trader backs the player who wins a set at $t=0$ and lays the same player after exactly 20 seconds, so that the time frame of the strategy corresponds to the length of our event window. ${ }^{35}$ Applying a standard commission of $5 \%$ on winning bets, such a simple trading rule yields $0.01 \%$ ( $p$-value $=0.91)$ for the 365 set events, $0.06 \%(p$-value $=0.95)$ for the 79 tie-break events, and $1.58 \%(p$-value $=0.04)$ for the 81 close set events. These results suggests that even if courtsiders are extremely quick to enter the back-lay strategy, the returns are significant only in the case of close set events. This is confirmed by Landi (2015), who shows that a trading strategy yields

\footnotetext{
${ }^{33}$ Hedging a trade by taking the opposite position on the same player is a strategy called "greening up". The name derives from the fact that by dynamically backing and laying the same player correctly, the trader can lock in a positive profit (indicated by a green number on the trading software) regardless of the outcome (Landi, 2015). Traders can also green up when they expect the odds to increase by laying first and backing later.

${ }^{34}$ The precise lay dollar amount yielding a so-called balanced trade is computed by multiplying the back amount by the back odds and dividing by the lay odds. Several online calculators, such as www.arbcruncher.com or www.backlaybettingcalculator.com, are readily available.

${ }^{35}$ Theoretically, if the traders expect the lay odds to further decrease after 20 seconds, they could wait longer before laying. Furthermore, for simplicity, we ignore the speed bump and assume that the new market orders are immediately matched.
} 
higher returns when applied to more balanced and uncertain situations because the odds react strongly and the liquidity is usually higher.

Finally, we estimate the returns from the same back-lay strategy for a slower trader starting the trade at second five and closing it at second 20. The returns are significantly lower and negative: $-2.65 \%(p$-value $=0.00)$ for the 365 set events, $-6.16 \%(p$-value $=0.00)$ for the 79 tie-break events, and $-6.46 \%(p$-value $=0.00)$ for the 81 close set events. The main reason for these negative returns is that slow traders receive much worse (lower) back odds.

Overall, these results show that only the fastest traders can profit from trading around important events, especially during balanced moments such as close sets, when information is more valuable. The strategy that we tested is very simple; therefore, the returns generated by courtsiders should be interpreted as lower-bound returns. More refined trading strategies yield higher returns if applied at the right moment, such as during balanced matches. ${ }^{36}$ However, one should note that, in practice, courtsiders have to cover their travel, stay, and entrance costs. Other factors, such as competition with other courtsiders, the presence of stadium security agents, low liquidity, and own trading mistakes, may also shrink the profits from such activity.

\section{Concluding remarks}

We analyze a setting characterized by speed differentials due to the presence of fasterinformed and faster-acting traders, so-called courtsiders. Similar to HFTs, courtsiders use fast technologies, algorithmic trading, and an optimal trading location-courtsiders trade from the stadium - to have a speed advantage. This setting offers a unique oppor-

\footnotetext{
${ }^{36}$ We calculate the returns for the same strategy but limit it to events when the overall match is balanced. We define a balanced moment as when the odds-implied probability of a player is between $25 \%$ and $75 \%$ (i.e., the mid-odds are between 1.33 and 4). Since a trader can observe whether the match is balanced at any time, this strategy is applicable in practice. After applying the "25\%-75\%" filter to the events, we find that a balanced back-lay strategy yields $2.33 \%(p$-value $=0.00)$ for 94 set events, $4.85 \%$ ( $p$-value=0.00) for 27 tie-break set events, and $7.33 \%(p$-value $=0.00)$ for 28 close set events.
} 
tunity to isolate the trading activity of fast traders and to examine how their trading affects price discovery and efficiency.

Our event study encompasses 365 set events from 141 men's singles matches at two major professional tennis tournaments. The event study results show that the betting prices adjust very quickly after important moments, such as the end of a set, before nonstadium traders have received the information via delayed TV images. Thus, courtsiding is occurring despite being officially prohibited by the tournament organizers.

Most important, we show that the prices are substantially affected by courtsiders's trading. Courtsiders accelerate the price discovery process and correctly impound new information into prices. Overall, they contribute between $60 \%$ and $70 \%$ of the full price reaction. This result supports Kyle's (1985) assertion that fast trading fosters efficient capital markets in the short term. Interestingly, our results show a stronger effect than that of Benos and Sagade (2016), who find, using trading data from the London Stock Exchange, that the HFT-induced price update accounts for $14 \%$ of the full price update. The Mincer-Zarnowitz efficiency test confirms that the betting prices are efficient around important news events, such as tie-break set and close set events, indicating that the betting odds correctly predict the outcome of the match. Finally, we estimate that a basic trading strategy yields positive trading returns. These returns are higher if the strategy is implemented after more important events.

Our results have important implications. First, we show that slow traders should abstain from betting during pivotal moments because they would, on average, lose money to fast traders. The speed differential put slower traders at a persistent informational disadvantage, thereby possibly reducing their willingness to participate in the marketplace, which may reduce price efficiency in general (Kyle, 1985). This could be tested using trading-account-level data, which would also allow examining whether slower traders adopt more passive trading strategies when they anticipate that they cannot compete with courtsiders on speed. Alternatively, one could examine betting data from the Aus- 
tralian Open. Because courtsiding at this tournament is now illegal by law, one would assume that no courtsiders are present at the stadium. It thus would be possible to examine the price discovery and efficiency of markets where courtsiders are banned. Finally, using the most recent betting data, one could investigate whether courtsiding has decreased over time since tournament organizers are increasing the number of security scouts and using of facial-recognition cameras to spot courtsiders who hide in the audience (Rothenberg, 2017).

The second implication concerns the speed bump, i.e., the market order processing delay of five seconds implemented by Betfair. We show that the speed bump is not effective. We believe that an exchange must carefully consider the choice of the length of the speed bump because depending on the technology used, TV images can be delayed by more than five seconds. Although Betfair warns their users that "live" images and scores may be delayed, it is conceivable that some slower traders cannot cancel their outstanding orders in a timely manner because the TV delay is too long. Second, even if they increase the length of the speed bump, the exchange also must consider that the speed bump can be circumvented by fast traders canceling their limit orders without delay at the cost of slower traders.

Interestingly, some public stock exchanges have introduced speed bumps and more are following. The IEX, a U.S. electronic stock exchange championed by Michael Lewis in his 2014 book "Flash Boys", has a speed bump of 350 microseconds intended to "even the playing field" between slow and fast traders (IEX, 2018). According to the IEX, although this delay is extremely small, it efficiently counteracts predatory HFT strategies (Laurence \& Annie, 2016). Other U.S. stock exchanges, which spent years accelerating trading, are now considering taking similar steps to slow it down (Bullock, 2016; McCrank, 2017). These changes offer new interesting research opportunities because speed bumps at stock exchanges might be circumvented similarly to those at betting exchanges. 
To conclude, our results show that in a setting with a speed differential, the fasterinformed and faster-acting traders quickly and correctly incorporate new information into prices. Nonetheless, we are not advocating for giving courtsiders an even larger information advantage. Instead, we firmly believe that, when debating the effects of fast trading (courtsiding) on a betting exchange or high-frequency trading on a financial market, the positive externalities of greater price discovery and efficiency around important news events should be weighed against the long-term adverse selection costs such as reduced participation rates. 


\section{A Appendix}

\section{A.1 Basic tennis rules}

This appendix introduces the basic rules and jargon of tennis. These rules are specific to Grand Slam tournaments and can be found on the website of the International Tennis Federation (www.itftennis.com). At the beginning of a match, a coin toss decides which player starts serving in the first game. Player 1 begins the match by serving in the first game of the first set-player 2 is the receiver. A player wins a point, sometimes referred to as a point game, if the opponent cannot return the ball. A game is won when one player wins four points with a two-point difference or when there is a two-point difference after a deuce, i.e., a score of 40-40 (3 points to 3 points in a game). During the match, points are scored "0", "15", "30", and "40". A player has a gamepoint if he needs one more point to win the game: if this player is the receiver, the situation is called a breakpoint. A break (of service) occurs when the receiver wins a game.

The players alternate serving every game, and they change ends after every oddnumbered game. A set is won when a player either wins six games with a two-game difference or, in the case of a tie-break, when the score for one player is 7:6. A player has a setpoint if he needs one more point to win a set: if this player is the receiver, he has a breakpoint to win the set.

A tie-break begins when the game score is tied at 6:6. During a tie-break game, points are scored "Zero", "1", "2", "3", etc. The tie-break continues until one player wins seven points, provided there is a margin of two points over the opponent (e.g., 7 5). If necessary, the tie-break game continues until a two-point margin is achieved (e.g., 8-6, 9-7, etc.) (International Tennis Federation, 2017). At Grand Slam tournaments, a tennis match is played as the best of five sets, meaning that the first player to win three sets wins the match. The fifth set does not have a tie-break; the set (and match) is won when one player wins two more games than the other player. 


\section{A.2 List of matches}

Table A.1 List of the matches included in our sample.

\begin{tabular}{|c|c|c|c|c|c|c|c|}
\hline Player 1 & Player 2 & Date & Stage & Player 1 & Player 2 & Date & Stage \\
\hline French Open: & & & & Wimbledon (cont.): & & & \\
\hline R.Gasquet & R.Stepanek & 23-May-2011 & 1 & A.Roddick & A.Murray & 3-Jul-2009 & 6 \\
\hline A.Clement & M.Berrer & 26-May-2011 & 2 & A.Roddick & R.Federer & 5-Jul-2009 & 7 \\
\hline J.Tipsarevic & R.Federer & 27-May-2011 & 3 & R.Federer & A.Falla & 21-Jun-2010 & 1 \\
\hline S.Darcis & G.Monfils & 27-May-2011 & 3 & R.Federer & I.Bozoljac & 23-Jun-2010 & 2 \\
\hline R.Gasquet & N.Djokovic & 29-May-2011 & 4 & R.Federer & A.Clement & 25-Jun-2010 & 3 \\
\hline G.Simon & R.Soderling & 30-May-2011 & 4 & P.Petzschner & R.Nadal & 26-Jun-2010 & 3 \\
\hline G.Monfils & R.Federer & 31-May-2011 & 5 & N.Djokovic & L.Hewitt & 28-Jun- 2010 & 4 \\
\hline A.Murray & J.Chela & 1-Jun-2011 & 5 & R.Federer & J.Melzer & 28-Jun- 2010 & 4 \\
\hline R.Nadal & R.Soderling & 1-Jun-2011 & 5 & R.Federer & T.Berdych & 30-Jun-2010 & 5 \\
\hline R.Federer & N.Djokovic & 3-Jun-2011 & 6 & R.Soderling & R.Nadal & 30-Jun-2010 & 5 \\
\hline R.Nadal & A.Murray & 3-Jun-2011 & 6 & J.Tsonga & A.Murray & 30-Jun-2010 & 5 \\
\hline R.Nadal & R.Federer & 5-Jun-2011 & 7 & A.Murray & R.Nadal & 2-Jul-2010 & 6 \\
\hline M.Llodra & G.Garcia-Lopez & 28-May-2012 & 1 & T.Berdych & N.Djokovic & 2-Jul-2010 & 6 \\
\hline I.Sijsling & G.Muller & 27-May-2012 & 1 & T.Berdych & R.Nadal & 4-Jul-2010 & 7 \\
\hline M.Berrer & J.Melzer & 27-May-2012 & 1 & M.Kukushkin & R.Federer & 21-Jun-2011 & 1 \\
\hline R.Federer & A.Ungur & 30-May-2012 & 2 & A.Mannarino & R.Federer & 23-Jun-2011 & 2 \\
\hline J.Del Potro & M.Cilic & 1-Jun-2012 & 3 & M.Baghdatis & N.Djokovic & 25-Jun-2011 & 3 \\
\hline F.Fognini & Jw.Tsonga & 1-Jun-2012 & 3 & D.Nalbandian & R.Federer & 25-Jun- 2011 & 3 \\
\hline G.Simon & S.Wawrinka & 1-Jun-2012 & 3 & A.Murray & R.Gasquet & 27-Jun-2011 & 4 \\
\hline J.Monaco & R.Nadal & 4-Jun- 2012 & 4 & M.Llodra & N.Djokovic & 27-Jun-2011 & 4 \\
\hline J.Tipsarevic & N.Almagro & 4-Jun-2012 & 4 & M.Youzhny & R.Federer & 27-Jun-2011 & 4 \\
\hline R.Federer & D. Goffin & 3-Jun-2012 & 4 & R.Nadal & M.Fish & 29-Jun-2011 & 5 \\
\hline N.Djokovic & A.Seppi & 3-Jun-2012 & 4 & J.Tsonga & R.Federer & 29-Jun-2011 & 5 \\
\hline N.Almagro & R.Nadal & 6-Jun-2012 & 5 & R.Nadal & A.Murray & 1-Jul-2011 & 6 \\
\hline D.Ferrer & A.Murray & 6-Jun-2012 & 5 & J.Tsonga & N.Djokovic & 1-Jul-2011 & 6 \\
\hline R.Federer & J.Del Potro & 5-Jun-2012 & 5 & R.Nadal & N.Djokovic & 3-Jul-2011 & 7 \\
\hline N.Djokovic & J.Tsonga & 5-Jun-2012 & 5 & R.Federer & A.Ramos & 25-Jun-2012 & 1 \\
\hline D.Ferrer & R.Nadal & 8-Jun-2012 & 6 & R.Federer & F.Fognini & 27-Jun-2012 & 2 \\
\hline N.Djokovic & R.Federer & 8-Jun-2012 & 6 & R.Federer & J.Benneteau & 29-Jun-2012 & 3 \\
\hline M.Raonic & M.Llodra & 29-May-2013 & 2 & R.Federer & X.Malisse & 2-Jul-2012 & 4 \\
\hline G.Monfils & E.Gulbis & 29-May-2013 & 2 & R.Federer & M.Youzhny & 4-Jul-2012 & 5 \\
\hline M.Przysiezny & R.Gasquet & 31-May-2013 & 2 & D.Ferrer & A.Murray & 4-Jul-2012 & 5 \\
\hline N.Djokovic & G.Pella & 30-May-2013 & 2 & A.Murray & J.Tsonga & 6-Jul-2012 & 6 \\
\hline V.Troicki & M.Cilic & 31-May-2013 & 3 & N.Djokovic & R.Federer & 6-Jul-2012 & 6 \\
\hline N.Davydenko & R.Gasquet & 1-Jun-2013 & 3 & R.Federer & A.Murray & 8-Jul-2012 & 7 \\
\hline T.Haas & J.Isner & 1-Jun-2013 & 3 & V.Hanescu & R.Federer & 24-Jun-2013 & 1 \\
\hline K.Anderson & D.Ferrer & 2-Jun-2013 & 4 & R.Nadal & S.Darcis & 24-Jun-2013 & 1 \\
\hline R.Nadal & K.Nishikori & 3-Jun-2013 & 4 & N.Djokovic & F.Mayer & 25-Jun-2013 & 1 \\
\hline J.Tsonga & R.Federer & 4-Jun-2013 & 5 & D.Ferrer & M.Alund & 25-Jun- 2013 & 1 \\
\hline T.Robredo & D.Ferrer & 4-Jun-2013 & 5 & A.Ramos & J.Del Potro & 25-Jun- 2013 & 1 \\
\hline R.Nadal & S.Wawrinka & 5-Jun-2013 & 5 & J.Tsonga & E.Gulbis & 26-Jun-2013 & 2 \\
\hline N.Djokovic & T.Haas & 5-Jun-2013 & 5 & F.Verdasco & J.Benneteau & 26-Jun-2013 & 2 \\
\hline D.Ferrer & Jw. Tsonga & 7-Jun-2013 & 6 & N.Djokovic & B.Reynolds & 27-Jun-2013 & 2 \\
\hline N.Djokovic & R.Nadal & 7-Jun-2013 & 6 & R.Gasquet & G.Soeda & 27-Jun-2013 & 2 \\
\hline R.Nadal & D.Ferrer & 9-Jun-2013 & 7 & J.Levine & J.Del Potro & 27-Jun-2013 & 2 \\
\hline V.Estrella Burgos & J.Janowicz & 25-May-2014 & 1 & J.Melzer & S.Stakhovsky & 28-Jun-2013 & 3 \\
\hline A.Dolgopolov & A.Ramos & 25-May-2014 & 1 & J.Janowicz & J.Melzer & 1-Jul-2013 & 4 \\
\hline G.Elias & D.Schwartzman & 25-May-2014 & 1 & M.Youzhny & A.Murray & 1-Jul-2013 & 4 \\
\hline R.Gasquet & B.Tomic & 27-May-2014 & 1 & N.Djokovic & T.Berdych & 3-Jul-2013 & 5 \\
\hline G.Monfils & V.Hanescu & 27-May-2014 & 1 & F.Verdasco & A.Murray & 3-Jul-2013 & 5 \\
\hline I.Karlovic & K.Anderson & 31-May-2014 & 3 & N.Djokovic & J.Del Potro & 5-Jul-2013 & 6 \\
\hline E.Gulbis & R.Federer & 1-Jun-2014 & 4 & J.Janowicz & A.Murray & 5-Jul-2013 & 6 \\
\hline T.Berdych & J.Isner & 1-Jun-2014 & 4 & N.Djokovic & A.Murray & 7-Jul-2013 & 7 \\
\hline G.Garcia-Lopez & G.Monfils & 2-Jun-2014 & 4 & G.Dimitrov & R.Harrison & 23-Jun-2014 & 1 \\
\hline M.Raonic & N.Djokovic & 3-Jun-2014 & 5 & A.Murray & D.Goffin & 23-Jun-2014 & 1 \\
\hline T.Berdych & E.Gulbis & 3-Jun-2014 & 5 & P.Lorenzi & R.Federer & 24-Jun-2014 & 1 \\
\hline G.Monfils & A.Murray & 4-Jun-2014 & 5 & S.Wawrinka & J.Sousa & 24-Jun-2014 & 1 \\
\hline R.Nadal & D.Ferrer & 4-Jun-2014 & 5 & G.Dimitrov & L.Saville & 25-Jun-2014 & 2 \\
\hline E.Gulbis & N.Djokovic & 6-Jun-2014 & 6 & A.Murray & B.Rola & 25-Jun-2014 & 2 \\
\hline R.Nadal & A.Murray & 6-Jun-2014 & 6 & G.Muller & R.Federer & 26-Jun-2014 & 2 \\
\hline R.Nadal & N.Djokovic & 8-Jun-2014 & 7 & L.Rosol & R.Nadal & 26-Jun-2014 & 2 \\
\hline Wimbledon: & & & & S. Wawrinka & Y-H.Lu & 26-Jun- 2014 & 2 \\
\hline G.Garcia-Lopez & R.Federer & 24-Jun-2009 & 2 & N.Djokovic & G.Simon & 27-Jun-2014 & 3 \\
\hline P.Kohlschreiber & R.Federer & 26-Jun-2009 & 3 & S.Giraldo & R.Federer & 28-Jun-2014 & 3 \\
\hline S.Wawrinka & J.Levine & 27-Jun-2009 & 3 & M.Kukushkin & R.Nadal & 28-Jun-2014 & 3 \\
\hline A.Murray & S.Wawrinka & 29-Jun-2009 & 4 & S.Wawrinka & D.Istomin & 30-Jun-2014 & 3 \\
\hline R.Soderling & R.Federer & 29-Jun-2009 & 4 & A.Murray & G.Dimitrov & 2-Jul-2014 & 5 \\
\hline T.Haas & N.Djokovic & 1-Jul-2009 & 5 & S.Wawrinka & R.Federer & 2-Jul-2014 & 5 \\
\hline L.Hewitt & A.Roddick & 1-Jul-2009 & 5 & N.Djokovic & G.Dimitrov & 4-Jul-2014 & 6 \\
\hline I.Karlovic & R.Federer & 1-Jul-2009 & 5 & R.Federer & M.Raonic & 4-Jul-2014 & 6 \\
\hline T.Haas & R.Federer & 3-Jul-2009 & 6 & N.Djokovic & R.Federer & 6-Jul-2014 & 7 \\
\hline
\end{tabular}

Notes: The table lists all 141 matches played at the French Open (Roland Garros) and at the Wimbledon Championships included in our sample. Stage indicates the tournament stage, from a first-round match (Stage=1) up to the final match (Stage=7). 


\section{A.3 Live tennis trading on Betfair}

In the following two paragraphs, we briefly illustrate the basics of live betting. Fig. A.1 shows a screenshot of the live order book during the match between Murray and Wawrinka taken from betfair.com on 9 June 2017 (this match, played at the French Open, serves only as an illustration and is not included in our sample). The order book presents the bets available to bet on the match winner: these are the bets previously placed by other traders that have not yet been matched. The third (fourth) column shows the current best back (lay) odds for each player. The available volumes (in $€$ ) are provided below the odds. According to Fig. A.1, the best odds to bet on Murray are 2.3, and it is possible to bet up to $€ 13,256$ at this price. As the inverse of the match odds can be interpreted as the player's probability of winning the match, after four hours of play, Wawrinka was perceived to be the favorite for the victory, with a probability of roughly $57 \%$.

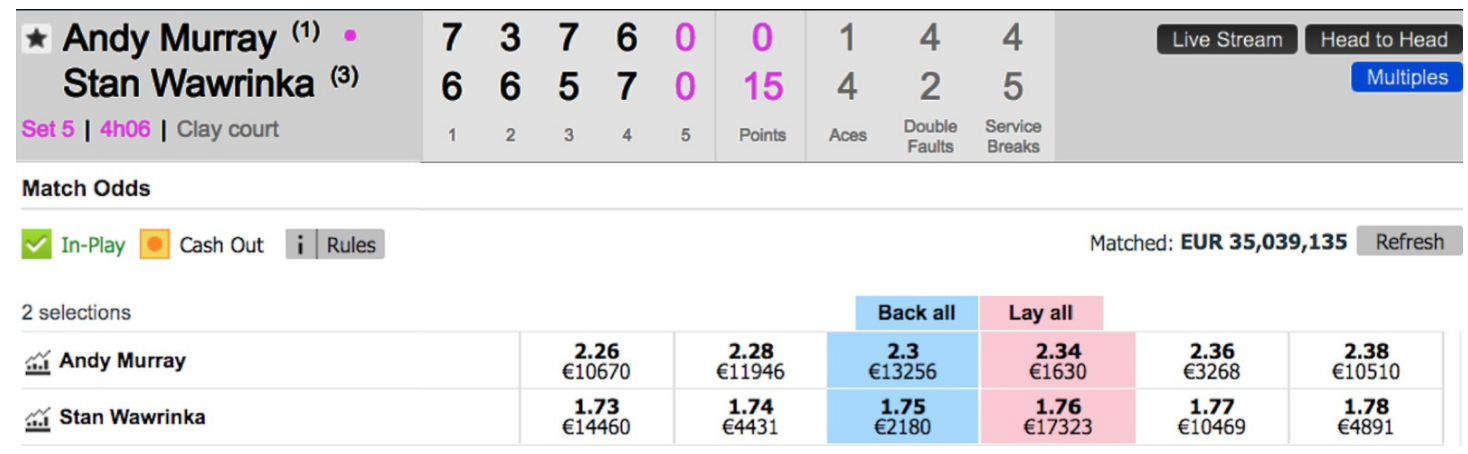

Figure A.1 Screenshot from betfair.com illustrating the interface. The screenshot was taken on 9 June 2017 during the match between Murray and Wawrinka at the French Open tournament. Four hours into the game, the total matched amount was $€ 35$ million (approximately $\$ 39$ million).

The simplest way to bet on Murray is to click on 2.3 (under "Back all") and enter the desired stake. By doing so, the trader (the backer) enters into a contract with one or more traders (the layers) who are taking the opposite position (against Murray) and offering odds of 2.3. Laying is an exclusive feature of betting exchanges in which layers play the role of a bookmaker offering odds. The backer is placing a market order, 
thereby matching the outstanding orders previously placed by the layers. Assuming that the backer puts $€ 10$ at stake and Murray wins the match, the payoff to the backer is $€ 13$ plus the initial $€ 10$ stake. Here, we ignore the $5 \%$ commission on winning bets collected by Betfair (no commission is paid when a loss is incurred). As betting is a zero-sum game, the layer loses $€ 13$. If the backer wishes to back Murray at the higher odds of 2.38, the backer places a limit order. If entered, this order shows up on the "Lay all" side of the order book and can be matched by a trader willing to lay Murray at those odds. 
A.4 Event study results in tabular form

Table A.2 Event study results.

\begin{tabular}{|c|c|c|c|c|c|c|}
\hline \multicolumn{7}{|c|}{ Panel A: set events $(N=365)$} \\
\hline Time $(t)$ & $A A R$ & t-statistic $\left(\theta_{1}\right)$ & p-value & $C A A R$ & t-statistic $\left(\theta_{2}\right)$ & p-value \\
\hline-2 & $0.20 \%$ & 1.56 & 0.118 & $0.20 \%$ & 1.56 & 0.118 \\
\hline-1 & $0.29 \%$ & 2.28 & 0.022 & $0.49 \%$ & 2.72 & 0.006 \\
\hline 0 & $0.23 \%$ & 1.81 & 0.071 & $0.73 \%$ & 3.27 & 0.001 \\
\hline 1 & $0.34 \%$ & 2.67 & 0.008 & $1.07 \%$ & 4.16 & 0.000 \\
\hline 2 & $0.51 \%$ & 4.02 & 0.000 & $1.58 \%$ & 5.52 & 0.000 \\
\hline 3 & $1.06 \%$ & 8.30 & 0.000 & $2.65 \%$ & 8.43 & 0.000 \\
\hline 4 & $0.40 \%$ & 3.16 & 0.002 & $3.05 \%$ & 9.00 & 0.000 \\
\hline 5 & $0.51 \%$ & 3.97 & 0.000 & $3.56 \%$ & 9.82 & 0.000 \\
\hline 6 & $1.51 \%$ & 11.77 & 0.000 & $5.07 \%$ & 13.18 & 0.000 \\
\hline 7 & $0.41 \%$ & 3.22 & 0.001 & $5.48 \%$ & 13.53 & 0.000 \\
\hline 8 & $0.07 \%$ & 0.52 & 0.600 & $5.55 \%$ & 13.05 & 0.000 \\
\hline 9 & $0.06 \%$ & 0.45 & 0.654 & $5.61 \%$ & 12.63 & 0.000 \\
\hline 10 & $0.26 \%$ & 2.01 & 0.044 & $5.87 \%$ & 12.69 & 0.000 \\
\hline 11 & $0.07 \%$ & 0.53 & 0.594 & $5.93 \%$ & 12.37 & 0.000 \\
\hline 12 & $0.22 \%$ & 1.70 & 0.090 & $6.15 \%$ & 12.39 & 0.000 \\
\hline 13 & $0.00 \%$ & -0.01 & 1.006 & $6.15 \%$ & 11.99 & 0.000 \\
\hline 14 & $-0.06 \%$ & -0.48 & 1.366 & $6.09 \%$ & 11.52 & 0.000 \\
\hline 15 & $0.08 \%$ & 0.64 & 0.521 & $6.17 \%$ & 11.35 & 0.000 \\
\hline 16 & $0.01 \%$ & 0.11 & 0.914 & $6.19 \%$ & 11.07 & 0.000 \\
\hline 17 & $0.00 \%$ & 0.00 & 1.000 & $6.19 \%$ & 10.79 & 0.000 \\
\hline 18 & $0.01 \%$ & 0.09 & 0.930 & $6.20 \%$ & 10.55 & 0.000 \\
\hline 19 & $0.11 \%$ & 0.89 & 0.373 & $6.31 \%$ & 10.50 & 0.000 \\
\hline 20 & $0.10 \%$ & 0.81 & 0.415 & $6.42 \%$ & 10.43 & 0.000 \\
\hline \multicolumn{7}{|c|}{ Panel B: tie-break set events $(N=79)$} \\
\hline-2 & $0.13 \%$ & 0.39 & 0.693 & $0.13 \%$ & 0.39 & 0.693 \\
\hline-1 & $0.90 \%$ & 2.64 & 0.008 & $1.04 \%$ & 2.15 & 0.032 \\
\hline 0 & $0.70 \%$ & 2.04 & 0.042 & $1.73 \%$ & 2.93 & 0.003 \\
\hline 1 & $1.22 \%$ & 3.56 & 0.000 & $2.95 \%$ & 4.32 & 0.000 \\
\hline 2 & $1.07 \%$ & 3.14 & 0.002 & $4.02 \%$ & 5.27 & 0.000 \\
\hline 3 & $3.48 \%$ & 10.17 & 0.000 & $7.50 \%$ & 8.96 & 0.000 \\
\hline 4 & $0.93 \%$ & 2.73 & 0.006 & $8.43 \%$ & 9.33 & 0.000 \\
\hline 5 & $0.97 \%$ & 2.84 & 0.005 & $9.40 \%$ & 9.73 & 0.000 \\
\hline 6 & $0.91 \%$ & 2.65 & 0.008 & $10.31 \%$ & 10.06 & 0.000 \\
\hline 7 & $1.53 \%$ & 4.47 & 0.000 & $11.84 \%$ & 10.96 & 0.000 \\
\hline 8 & $-0.01 \%$ & -0.02 & 1.013 & $11.83 \%$ & 10.44 & 0.000 \\
\hline 9 & $0.00 \%$ & -0.01 & 1.011 & $11.83 \%$ & 9.99 & 0.000 \\
\hline 10 & $1.16 \%$ & 3.40 & 0.001 & $12.99 \%$ & 10.54 & 0.000 \\
\hline 11 & $-0.01 \%$ & -0.01 & 1.012 & $12.98 \%$ & 10.16 & 0.000 \\
\hline 12 & $-0.04 \%$ & -0.11 & 1.091 & $12.94 \%$ & 9.78 & 0.000 \\
\hline 13 & $0.21 \%$ & 0.61 & 0.540 & $13.15 \%$ & 9.63 & 0.000 \\
\hline 14 & $0.25 \%$ & 0.74 & 0.461 & $13.40 \%$ & 9.52 & 0.000 \\
\hline 15 & $0.01 \%$ & 0.04 & 0.970 & $13.42 \%$ & 9.26 & 0.000 \\
\hline 16 & $-0.08 \%$ & -0.22 & 1.174 & $13.34 \%$ & 8.96 & 0.000 \\
\hline 17 & $-0.04 \%$ & -0.11 & 1.089 & $13.30 \%$ & 8.71 & 0.000 \\
\hline 18 & $-0.12 \%$ & -0.35 & 1.275 & $13.18 \%$ & 8.42 & 0.000 \\
\hline 19 & $-0.48 \%$ & -1.42 & 1.843 & $12.70 \%$ & 7.93 & 0.000 \\
\hline 20 & $0.03 \%$ & 0.10 & 0.921 & $12.73 \%$ & 7.77 & 0.000 \\
\hline \multicolumn{7}{|c|}{ Panel C: close set events $(N=81)$} \\
\hline-2 & $0.54 \%$ & 1.54 & 0.123 & $0.54 \%$ & 1.54 & 0.123 \\
\hline-1 & $1.09 \%$ & 3.13 & 0.002 & $1.63 \%$ & 3.30 & 0.001 \\
\hline 0 & $0.51 \%$ & 1.46 & 0.145 & $2.13 \%$ & 3.54 & 0.000 \\
\hline 1 & $1.07 \%$ & 3.06 & 0.002 & $3.20 \%$ & 4.59 & 0.000 \\
\hline 2 & $1.47 \%$ & 4.22 & 0.000 & $4.67 \%$ & 6.00 & 0.000 \\
\hline 3 & $3.82 \%$ & 10.97 & 0.000 & $8.49 \%$ & 9.95 & 0.000 \\
\hline 4 & $1.12 \%$ & 3.22 & 0.001 & $9.61 \%$ & 10.43 & 0.000 \\
\hline 5 & $1.26 \%$ & 3.61 & 0.000 & $10.87 \%$ & 11.03 & 0.000 \\
\hline 6 & $1.15 \%$ & 3.31 & 0.001 & $12.02 \%$ & 11.51 & 0.000 \\
\hline 7 & $1.54 \%$ & 4.43 & 0.000 & $13.56 \%$ & 12.32 & 0.000 \\
\hline 8 & $0.05 \%$ & 0.15 & 0.882 & $13.61 \%$ & 11.79 & 0.000 \\
\hline 9 & $0.08 \%$ & 0.24 & 0.814 & $13.70 \%$ & 11.36 & 0.000 \\
\hline 10 & $1.28 \%$ & 3.67 & 0.000 & $14.97 \%$ & 11.93 & 0.000 \\
\hline 11 & $-0.05 \%$ & -0.14 & 1.109 & $14.93 \%$ & 11.46 & 0.000 \\
\hline 12 & $0.84 \%$ & 2.40 & 0.016 & $15.76 \%$ & $\begin{array}{l}11.40 \\
11.69\end{array}$ & 0.000 \\
\hline 13 & $0.46 \%$ & 1.33 & 0.183 & $16.23 \%$ & 11.65 & 0.000 \\
\hline 14 & $0.17 \%$ & 0.47 & 0.636 & $16.39 \%$ & 11.42 & 0.000 \\
\hline 15 & $0.00 \%$ & 0.00 & 1.000 & $16.39 \%$ & 11.10 & 0.000 \\
\hline 16 & $-0.03 \%$ & -0.07 & 1.059 & $16.37 \%$ & 10.78 & 0.000 \\
\hline 17 & $0.04 \%$ & 0.13 & 0.898 & $16.41 \%$ & 10.54 & 0.000 \\
\hline 18 & $-0.15 \%$ & -0.44 & 1.337 & $16.26 \%$ & 10.19 & 0.000 \\
\hline 19 & $-0.28 \%$ & -0.79 & 1.573 & $15.98 \%$ & 9.79 & 0.000 \\
\hline 20 & $-0.73 \%$ & -2.09 & 1.964 & $15.25 \%$ & 9.13 & 0.000 \\
\hline
\end{tabular}

Notes: The table reports the average abnormal returns $(A A R)$ and the cumulative average abnormal returns $(C A A R)$ over the event window. 


\section{References}

Anderson, J. (2015). 2015 is the year of anniversaries in sports law (Vol. 15). Springer.

Balp, G., \& Strampelli, G. (2018). Preserving capital markets efficiency in the highfrequency trading era. Bocconi Legal Studies, Working Paper.

Baron, M., Brogaard, J., Hagströmer, B., \& Kirilenko, A. (2017). Risk and return in high-frequency trading. Foster School of Business, Working Paper.

Benos, E., \& Sagade, S. (2016). Price discovery and the cross-section of high-frequency trading. Journal of Financial Markets, 30, 54-77.

Betfair. (2015). Annual report. Retrieved 2017-06-10, from www.paddypowerbetfair .com/ /media/Files/P/Paddy-Power-Betfair/archive/annual-report-general -meeting/betfair/annual-report-2015.pdf

Betfair. (2017a). Rules and regulations. Retrieved 2017-06-02, from www.betfair.com/ aboutUs/Rules.and.Regulations/

Betfair. (2017b). Terms and conditions. Retrieved 2017-07-07, from http://www.betfair .com/aboutUs/Terms.and.Conditions/\#terms-betting-general

Biais, B., Foucault, T., et al. (2014). HFT and market quality. Bankers, Markets $\&$ Investors, 128(1), 5-19.

Boehmer, E., Li, D., \& Saar, G. (2018). The competitive landscape of high-frequency trading firms. The Review of Financial Studies, 31(6), 2227-2276.

Brogaard, J., Hendershott, T., \& Riordan, R. (2014). High-frequency trading and price discovery. The Review of Financial Studies, 27(8), 2267-2306.

Brown, A. (2012). Evidence of in-play insider trading on a UK betting exchange. Applied Economics, 44(9), 1169-1175.

Brown, A., Reade, J. J., \& Vaughan Williams, L. (2018). When are prediction market prices most informative? International Journal of Forecasting.

Brown, A., \& Yang, F. (2017). Slowing down fast traders: Evidence from the Betfair speed bump. Journal of Financial Markets (forthcoming).

Bullock, N. (2016). Nasdaq seeks speed bump in attempt to prioritise retail orders. The Financial Times. Retrieved 2018-07-01, from https://www.ft.com/content/ b6e20342-b1d7-11e6-a37c-f4a01f1b0fa1

Carrion, A. (2013). Very fast money: High-frequency trading on the NASDAQ. Journal of Financial Markets, 16(4), 680-711.

Chaboud, A. P., Chiquoine, B., Hjalmarsson, E., \& Vega, C. (2014). Rise of the machines: Algorithmic trading in the foreign exchange market. The Journal of Finance, 69(5), 2045-2084. 
Choi, D., \& Hui, S. K. (2014). The role of surprise: Understanding overreaction and underreaction to unanticipated events using in-play soccer betting market. Journal of Economic Behavior \& Organization, 107(Part B), 614-629.

Chordia, T., Goyal, A., Lehmann, B., \& Saar, G. (2013). High-frequency trading. The Journal of Financial Markets, 16, 637-645.

Chordia, T., Green, T. C., \& Kottimukkalur, B. (2017). Rent seeking by low latency traders: Evidence from trading on macroeconomic announcements. Review of Financial Studies (forthcoming).

Cox, S. (2015). Why tennis courtsiding was my dream job. BBC News Magazine. Retrieved 2017-06-16, from www.bbc.com/news/magazine-32402945

Croxson, K., \& Reade, J. (2014). Information and efficiency: Goal arrival in soccer betting. The Economic Journal, 124(575), 62-91.

Dickson, C. (2015). Courtsiding in sport: Cheating, sharp practice or merely irritating? Sports Law eJournal.

Dugast, J., Foucault, T., et al. (2014). False news, informational efficiency, and price reversals. Banque de France, Working Paper.

Foucault, T., Hombert, J., \& Roşu, I. (2016). News trading and speed. The Journal of Finance, 71(1), 335-382.

Haldane, A. G. (2012). The race to zero. In The global macro economy and finance (pp. 245-270). Springer.

Hasbrouck, J., \& Saar, G. (2013). Low-latency trading. Journal of Financial Markets, 16(4), 646-679.

Hays, T. (2017). Behind the shadowy practice of courtsiding at the US Open. The Washington Times. Retrieved 2018-07-10, from https://www.washingtontimes.com/ news/2017/sep/8/behind-the-shadowy-practice-of-courtsiding-at-the-/

Hendershott, T., Jones, C. M., \& Menkveld, A. J. (2011). Does algorithmic trading improve liquidity? The Journal of Finance, 66(1), 1-33.

Hu, G. X., Pan, J., \& Wang, J. (2017). Early peek advantage? Efficient price discovery with tiered information disclosure. Journal of Financial Economics, 126(2), 399421.

Hutchins, B. (2014). Game, Set, Cash! Inside the secret world of international tennis trading. Nero.

IEX. (2018). Retrieved 2018-07-03, from https://iextrading.com/

International Tennis Federation. (2017). ITF rules of tennis. Retrieved 2017-06-16, from http://www.itftennis.com/officiating/rulebooks/rules-of-tennis

Jackson, R., Jiang, W., \& Mitts, J. (2016). How quickly do markets learn? Private 
information dissemination in a natural experiment. Columbia University, Working Paper.

Jarrow, R. A., \& Protter, P. (2012). A dysfunctional role of high frequency trading in electronic markets. International Journal of Theoretical and Applied Finance, $15(3)$.

Jones, C. M. (2013). What do we know about high-frequency trading? Columbia University, Working Paper.

Ke, B., Huddart, S., \& Petroni, K. (2003). What insiders know about future earnings and how they use it: Evidence from insider trades. Journal of Accounting and Economics, 35(3), 315-346.

Kirilenko, A., Kyle, A. S., Samadi, M., \& Tuzun, T. (2017). The flash crash: Highfrequency trading in an electronic market. The Journal of Finance, 72(3), 967998.

Kooij, W. J., Stokking, H. M., van Brandenburg, R., \& de Boer, P.-T. (2014). Playout delay of TV signals: Measurement system design, validation and results. In Proceedings of the 2014 ACM international conference on interactive experiences for $T V$ and online video (pp. 23-30). ACM.

Kyle, A. S. (1985). Continuous auctions and insider trading. Econometrica, 1315-1335.

Landi, G. (2015). Betting exchange: La rivoluzione del trading sportivo.

Laurence, A., \& Annie, M. (2016). Quicktake Q\&A: IEX puts speed bump in path of fastest trading. Bloomberg.

MacKinlay, A. C. (1997). Event studies in economics and finance. Journal of Economic Literature, 35(1), 13-39.

McCrank, J. (2017). U.S. stock exchanges that spent decades speeding up markets with cutting-edge technology are now rushing to slow them down. Reuters. Retrieved 2018-07-01, from https://www.reuters.com/article/ us-exchanges-speedbumps-idUSKBN17615R

Menkveld, A. J. (2016). The economics of high-frequency trading: Taking stock. Annual Review of Financial Economics, 8, 1-24.

Menkveld, A. J. (2018). High-frequency trading as viewed through an electron microscope. Financial Analysts Journal, 74 (2), 24-31.

Menkveld, A. J., \& Yueshen, B. (2018). The flash crash: A cautionary tale about highly fragmented markets. Management Science (forthcoming).

Mincer, J. A., \& Zarnowitz, V. (1969). The evaluation of economic forecasts. In Economic forecasts and expectations: Analysis of forecasting behavior and performance (pp. 3-46). NBER. 
O'Hara, M. (2015). High frequency market microstructure. Journal of Financial Economics, 116(2), 257-270.

Parliament of Victoria. (2013). Crimes amendment (integrity in sports) act.

Riordan, R., \& Storkenmaier, A. (2012). Latency, liquidity and price discovery. Journal of Financial Markets, 15(4), 416-437.

Rogers, J. L., Skinner, D. J., \& Zechman, S. L. (2017). Run EDGAR run: SEC dissemination in a high-frequency world. Journal of Accounting Research, 55(2), 459-505.

Rothenberg, B. (2017). Man barred from open last year is arrested after returning. The New York Times. Retrieved 2018-07-02, from https://www.nytimes.com/2017/09/ $02 /$ sports/tennis/us-open-courtsiding-arrest.html

Securities and Exchange Commission. (2014). Equity market structure literature review, part II: High frequency trading. Retrieved 2017-07-01, from https://www.sec.gov/ marketstructure/research/hft_lit_review_march_2014.pdf

Securities and Exchange Commission. (2017). Form 4. Statement of changes of beneficial ownership of securities. Retrieved 2017-06-01, from www.sec.gov/files/form4data\% 2C0.pdf

Shkilko, A., \& Sokolov, K. (2018). Every cloud has a silver lining: Fast trading, microwave connectivity and trading costs. Available at SSRN 2848562. Retrieved 2018-07-12, from https://papers.ssrn.com/sol3/papers.cfm?abstract_id=2848562

Townend, M. (2016). Tennis gambling market second only to football for bookmakers after boom in online and in-play betting. Daily Mail Online. Retrieved 2018-07-04, from http://www.dailymail.co.uk/sport/tennis/article-3405544/Tennis-gambling -market-second-football-bookmakers-boom-online-play-betting.html

UK Gambling Commission. (2016). In-play (in-running) betting: position paper. Retrieved 2018-07-02, from http://www.gamblingcommission.gov.uk/ for-gambling-businesses/Compliance/Sector-specific-compliance/Betting/ In-play-betting.aspx

Vaughan Williams, L. (1999). Information efficiency in betting markets: A survey. Bulletin of Economic Research, 51(1), 1-39.

Vaughan Williams, L. (2009). Information efficiency in financial and betting markets. Cambridge University Press.

Weller, B. M. (2016). Efficient prices at any cost: Does algorithmic trading deter information acquisition? Duke University, Working paper.

Yadav, Y. (2016). Insider trading and market structure. UCLA Law Review, 63(4). 